\title{
Understanding interactions between biomaterials and biological systems using proteomics
}

Citation for published version (APA):

Othman, Z., Pastor, B. C., van Rijt, S., \& Habibovic, P. (2018). Understanding interactions between biomaterials and biological systems using proteomics. Biomaterials, 167, 191-204. https://doi.org/10.1016/j.biomaterials.2018.03.020

Document status and date:

Published: 01/06/2018

DOI:

10.1016/j.biomaterials.2018.03.020

Document Version:

Publisher's PDF, also known as Version of record

Document license:

Taverne

Please check the document version of this publication:

- A submitted manuscript is the version of the article upon submission and before peer-review. There can be important differences between the submitted version and the official published version of record.

People interested in the research are advised to contact the author for the final version of the publication, or visit the DOI to the publisher's website.

- The final author version and the galley proof are versions of the publication after peer review.

- The final published version features the final layout of the paper including the volume, issue and page numbers.

Link to publication

\footnotetext{
General rights rights.

- You may freely distribute the URL identifying the publication in the public portal. please follow below link for the End User Agreement:

www.umlib.nl/taverne-license

Take down policy

If you believe that this document breaches copyright please contact us at:

repository@maastrichtuniversity.nl

providing details and we will investigate your claim.
}

Copyright and moral rights for the publications made accessible in the public portal are retained by the authors and/or other copyright owners and it is a condition of accessing publications that users recognise and abide by the legal requirements associated with these

- Users may download and print one copy of any publication from the public portal for the purpose of private study or research.

- You may not further distribute the material or use it for any profit-making activity or commercial gain

If the publication is distributed under the terms of Article $25 \mathrm{fa}$ of the Dutch Copyright Act, indicated by the "Taverne" license above, 
Review

\title{
Understanding interactions between biomaterials and biological systems using proteomics
}

\author{
Ziryan Othman a, Berta Cillero Pastor ${ }^{\text {b }}$, Sabine van Rijt a , Pamela Habibovic a, * \\ a MERLN Institute for Technology-Inspired Regenerative Medicine, Department of Instructive Biomaterials Engineering, Maastricht University, \\ Universiteitssingel 40, 6229 ER Maastricht, The Netherlands \\ b The Maastricht Multimodal Molecular Imaging Institute (M4I), Division of Imaging Mass Spectrometry, Maastricht University, Universiteitssingel 50, 6229 \\ ER Maastricht, The Netherlands
}

\section{A R T I C L E I N F O}

\section{Article history:}

Received 29 October 2017

Received in revised form

2 March 2018

Accepted 12 March 2018

Available online 12 March 2018

\section{Keywords:}

Biomaterials

Regenerative medicine

Proteins

High-content screening

Mass spectrometry

\begin{abstract}
A B S T R A C T
The role that biomaterials play in the clinical treatment of damaged organs and tissues is changing. While biomaterials used in permanent medical devices were required to passively take over the function of a damaged tissue in the long term, current biomaterials are expected to trigger and harness the selfregenerative potential of the body in situ and then to degrade, the foundation of regenerative medicine. To meet these different requirements, it is imperative to fully understand the interactions biomaterials have with biological systems, in space and in time. This knowledge will lead to a better understanding of the regenerative capabilities of biomaterials aiding their design with improved functionalities (e.g. biocompatibility, bioactivity). Proteins play a pivotal role in the interaction between biomaterials and cells or tissues. Protein adsorption on the material surface is the very first event of this interaction, which is determinant for the subsequent processes of cell growth, differentiation, and extracellular matrix formation. Against this background, the aim of the current review is to provide insight in the current knowledge of the role of proteins in cell-biomaterial and tissue-biomaterial interactions. In particular, the focus is on proteomics studies, mainly using mass spectrometry, and the knowledge they have generated on protein adsorption of biomaterials, protein production by cells cultured on materials, safety and efficacy of new materials based on nanoparticles and the analysis of extracellular matrices and extracellular matrix-derived products. In the outlook, the potential and limitations of this approach are discussed and mass spectrometry imaging is presented as a powerful technique that complements existing mass spectrometry techniques by providing spatial molecular information about the materialbiological system interactions.
\end{abstract}

๑) 2018 Elsevier Ltd. All rights reserved.

\section{Introduction}

Implants based on natural or synthetic materials have a long history of use as replacements for damaged, malfunctioning organs and tissues [1,2]. Initially the extent of use of (predominantly natural) materials was driven by their availability. However, failure often occurred as a consequence of adverse body responses, infections, and in general the lack of understanding of the interactions between the body and these materials [3,4]. Since the start of the 20th century, increasing insights in materials science as well as molecular and cell biology have emerged into the field of

\footnotetext{
* Corresponding author.

E-mail address: p.habibovic@maastrichtuniversity.nl (P. Habibovic).
}

biomaterials science. Biomaterials, in particular in the form of medical devices, have improved quality of life of many patients with dental implants, artificial joints, ocular lenses and vascular stents, being the well-known examples. With the main role of these devices to replace the damaged tissue and passively take over its function, their selection and manufacturing are predominantly based on mimicking the chemical and physical properties of the natural tissue, while causing minimal foreign body response.

With the emergence of tissue engineering in the late 1980s and 1990 s, the expected role of materials for biomedical applications started to shift from replacement of damaged and diseased body parts to stimulation of desired biological responses in the body, with the final aim to initiate inherent regenerative mechanisms and regain natural function [1]. To achieve this goal, biomaterials are used as (temporary) carriers of cells and/or biological molecules. 
Probably the best-known example of this approach is the clinical use of INFUSE Bone Graft, a construct based on a degradable collagen sponge carrier and recombinant human bone morphogenetic protein 2 (rhBMP2), developed to treat large, critical-sized bone defects, which do not heal spontaneously. This and other constructs based on rhBMPs were developed as an alternative to autologous bone grafts, the availability of which is limited, for multiple clinical applications such as spinal fusion, internal fixation of fractures, and filling of bone voids [5]. Nevertheless, the clinical use of products based on BMPs is still associated with a number of side effects, heterotopic bone formation being among the most important ones [6,7]. This side effect is associated with supraphysiological amounts of the growth factor used in clinical practice, as well as with insufficient control over its release kinetics from the carrier material, a result of an incomplete understanding of the interaction between the protein and the carrier material.

In general, despite the promise of conventional tissue engineering approaches, few products based on materials combined with cells and/or growth factors have actually reached patients. While unsatisfying performance and adverse side effects are important reasons for the limited clinical translation of this technology, complex regulatory pathways and high costs are at least as important. As a result, the focus is now shifting to the design and development of smart, instructive biomaterials that are able to attract and accumulate relevant cells and growth factors in situ, to initiate and stimulate the process of regeneration without the need for pre-operative addition of cells or biologics. Such instructive materials, often based on polymers, ceramics and their combinations, are expected to fully degrade inside the body after fulfilling the role for which they were initially designed [8-13].

Clearly, with this changing role of biomaterials from passive to instructive, and even responsive, in time and space, the need for exactly understanding the biomaterials' interactions with biological systems is of utmost importance. This comprehension of cell-material and tissue-material interactions is not only important to satisfy scientific curiosity, but it is a prerequisite for our ability to design new, improved biomaterials. Moreover, currently the pace at which biomaterials reach the clinic is slow. One of the major bottlenecks is that there is a poor correlation between the in vitro and in vivo performance of biomaterials [14,15]. Knowledge of the global cellular and molecular events that occur when biomaterials interact with a complex biological system can lead to a better prediction on materials behaviour going from an in vitro to an in vivo setting, and ultimately to a better understanding of why certain materials succeed in the clinic where others fail. Thus, improved knowledge of tissue-material interactions will tremendously aid future material design and ultimately faster clinical development of biomaterials [16-19].

Understanding the interactions at the biomaterial-biological interface is, however, not a trivial task. Various material properties, including chemical composition, structural characteristics at various length scales and mechanical properties, have been shown to act as potential cues instructing and directing biological processes [20-23]. Because these properties are often interconnected, it is difficult to make a direct correlation between individual properties and biological responses.

A particularly powerful tool to describe the interactions between cells/tissues and materials is by protein actions, since protein adsorption on the material surface is one of the very first events in this interaction [24]. Proteins adsorbed to the material surface facilitate and control cell adhesion and the subsequent cellular events, including cell proliferation and differentiation [25]. The quantity and properties of the adsorbed proteins are highly dependent on the material (surface) properties [26-28]. In turn, the first layer of attached proteins determines the formation and content of subsequent protein layers, affecting the fate of the material itself, in terms of e.g. regenerative capacity [29], biocompatibility [30], and degradation [31]. Various methods exist to study the behaviour of proteins, including their transcription, posttranslational modifications, conformation, spliced variants or intraand extracellular spatial distributions. While methods such as Western blot and immunoassays are suitable for determining protein behaviour on biomaterials in a limited number of samples and for a limited number of proteins, large-scale characterisation methods are preferred to provide broader protein content of a cell, tissue or organism. Proteomics based on mass spectrometry (MS), is a large-scale study of proteins that reside within a cell, organism or system $[32,33]$. Such studies are particularly interesting to obtain a more global and integrated view of biology by studying the proteome of a biological environment, rather than each protein individually [34]. When coupled to other techniques, such as e.g. twodimensional gel electrophoresis (2-DE), complex protein samples can be investigated with high sensitivity and reproducibility especially when proteins have been previously labelled with spectrally resolvable fluorophore agents (CyDyes) [35-39] (Fig. 1). Moreover, with appropriate sample preparation such as the depletion of highly abundant proteins from complex biological samples [36], or multidimensional phase separation based on liquid chromatography coupled to MS (also referred to as shotgun proteomics) [40,41], this technology has even allowed for the detection of proteins present in small amounts. However, reliable MS data depend on many other biological and technical variables such as sample type, sample collection methods, and method optimisation and instrumentation [36,42].

To complement a previously published review that provides an overview of various high-throughput and high-content techniques used to study biomaterials in regenerative medicine, including various proteomics techniques [43], the aim of the current paper is to describe the knowledge gained on cell-biomaterial and tissue-biomaterial interactions by studying proteins, with special emphasis on MS-based studies. The objective is to describe the type of knowledge that is gained from using proteomic approaches and discuss how these methods can potentially affect the development of new biomaterials. In the first part, the focus is on the adsorption of proteins on material surfaces. The importance of understanding the process of protein adsorption and the effects of various material properties on this process is described. In the second part, the

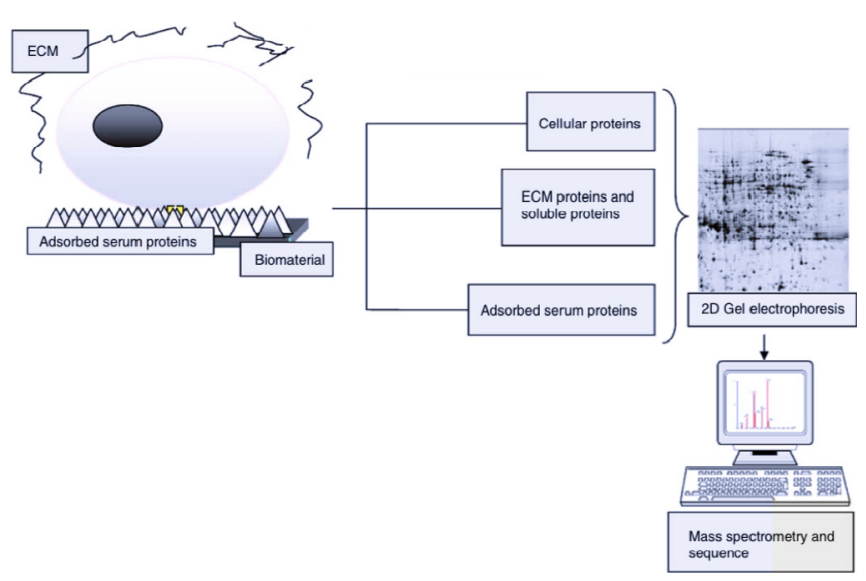

Fig. 1. Schematic illustration showing a proteomic approach based on two-DE gel electrophoresis and subsequent MS analysis, adapted from Ref. [16]; two-DE gel reduces the complexity by resolving the proteins by charge (isoelectric point, $\mathrm{pI}$ ) in the first dimension and further separating proteins by mass in the second dimension on gels. Then the protein samples can be consequently analysed by MS. 
effects of material properties on the secretion of proteins by cells in contact with the material are covered. The third part is dedicated to the study of proteins in interactions between nanoparticles/ nanoparticle-based materials and biological systems. The fourth section focuses on the use of proteomics to understand extracellular matrix (ECM) and ECM-derived biomaterials. Finally, the outlook provides a summary of the existing knowledge and discusses the limitations of the existing MS techniques and the possibilities of new MS-based techniques to further advance the knowledge of cell-material and tissue-material interactions.

\section{Protein adsorption on biomaterials}

Protein adsorption on a biomaterial surface is the first event that occurs in any biological system [44]. Understanding the behaviour of an interfacial protein thus offers a good opportunity to improve surface design for implants used for various medical applications. However, there are many factors that affect protein adsorption such as the chemical and physical properties of the biomaterial, and external factors of the surrounding solvent system such as $\mathrm{pH}$, temperature, ionic strength, and concentration of different protein species in a buffer solution [45]. The nature of the proteins themselves (e.g. size and structure) also affect the adsorption behaviour. For example, small proteins such as lysozyme, $\beta$-lactoglobulin, or $\alpha$ chymotrypsin are known to have a relatively low tendency for structural modification upon adsorption. In contrast, intermediatesized proteins like albumin, transferrin, and immunoglobulins possess a higher ability to undergo conformational reorientation once in contact with a surface, with in general, larger proteins binding more strongly to a surface compared to smaller proteins [46]. Moreover, often these proteins can expel pre-adsorbed proteins. Thus, protein adsorption is a complex and dynamic process often accomplished with an overlap of transport and repulsion that is affected by many internal and external factors [46]. In this section the effects of protein adsorption on the biological response and strategies that aim to understand and modulate the protein adhesion properties of materials are discussed.

\subsection{Effects of protein adsorption on the biological response}

Upon implantation of biomaterials, protein adsorption on the surface occurs within seconds $[44,47,48]$, whereas circulating cells usually do not have direct access to the material surface. Therefore, the body's response to the implants are determined mostly by the extent and nature of the initial protein adsorption [47,48]. Many studies have shed light on how the adsorbed proteins influence the inflammatory response [49], in particular with regard to the role of abundant plasma proteins including albumin [50,51], immunoglobulins [52] and fibrinogen [53,54]. For example, studies have shown that albumin-coated surfaces reduce the acute inflammatory response as they prevent the attraction of inflammatory cells [47]. Fibrinogen-coated surfaces, on the other hand, have shown to play a significant role in inducing inflammatory responses [47,55]. In one such study a polystyrene surface coated with fibrinogen facilitated platelet adhesion and activation, which subsequently led to the development of surface-induced thrombosis [56] (Fig. 2). Adsorbed immunoglobulin has been shown to significantly prevent cell distribution and in addition, to reduce metabolic activity of attached cells [57].

Understanding the role abundant plasma proteins play in modulating biological responses can also be used to steer a specific reaction by coating the surface of biomaterials with proteins before implantation. For instance, surface coated with collagen and fibronectin can promote cell adhesion and cell spreading $[45,58,59]$. Coating a surface with albumin can prevent other

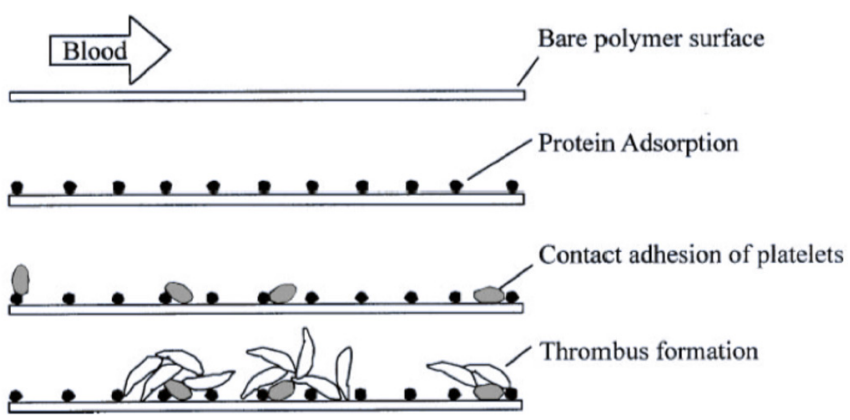

Fig. 2. Schematic illustration of protein adsorption on the surface of biomaterials leading to thrombus formation. Reprinted, with permission from Oleschuk et al. [64].

pathological proteins to be adsorbed on the same surface, which can lead to a lower inflammatory response [45].

\subsection{Prevention of nonspecific protein binding}

While control over protein adsorption to surfaces of biomaterials is important in determining the cellular response to these materials, preventing nonspecific protein binding is of equal importance. The general thought is that proteins adsorb in monolayers, and they cannot stack on top of each other. However, it is also known that already adsorbed proteins can be displaced or replaced by other proteins, a phenomenon known as the Vroman effect [46]. Often, proteins with relatively small molecular weight are replaced by larger proteins on the surfaces of biomaterials. These large proteins are unable to preserve their native structure, which could eventually lead to unfavourable reactions such as blood clots or fibrous capsules forming around the implant [60]. In contrast to the consensus that proteins adsorb to surfaces of biomaterials in monolayers, the ability of proteins to adsorb on top of each other was shown in a study by Holmberg and Hou [61], who analysed the adsorption of albumin and fibrinogen onto poly(ethylene terephthalate) (PET) and glass surfaces by selective labelling. The results revealed that fibrinogen could adhere onto a pre-adsorbed albumin layer, but at the same time, pre-adsorbed albumin reduced the amount of adsorbed fibrinogen. The authors concluded that protein replacement was not the major process occurring on the surfaces and that the total amount of protein was higher when the proteins were sequentially exposed to the surface compared to the conditions where proteins were added simultaneously. Using biomaterials that prevent the adsorption of specific proteins can also be used as a strategy to improve biocompatibility of implants. For example, Wang et al. [62] showed that proteins like vitronectin, thrombin, fibrinogen and complement component $\mathrm{C} 3$ were adsorbed in significantly lower amounts on hydrogels, which correlated with a significant lower number of monocytes, compared to polystyrene culture plates. Also the medium is important in determining the adsorption effect. For example, Serpooshan et al. [63] utilised label-free liquid chromatographytandem mass spectrometry (LC-MS/MS) to characterise proteins that were adsorbed on collagen type 1 gels upon immersion in different biological fluids, such as fetal bovine serum, and C57 mouse serum and plasma. After two hours of incubation, the data indicated that gels yielded several common and unique proteins. For example, gels immersed in serum had more unique proteins (e.g., Ighg1, Orm1 and 2, Ambp, and Apoa proteins) than those incubated in plasma (Igh-VX24 heavy chain V), suggesting that plasma contains factors that prevent serum proteins to adhere to the collagen surface. Serum contains plasma but without clotting factors, which means that proteins might have higher affinity for the collagen gel surface compared to the plasma environment. 


\subsection{The effects of physicochemical material properties on protein adsorption}

Several recent studies have investigated to which extent protein adsorption can be controlled by modulating the physicochemical and structural properties of biomaterials. Specifically, changing the surface roughness can have a big effect on the layer composition of the adsorbed proteins. For example, the importance of surface roughness is demonstrated by the fact that plasma-etched, but not untreated tissue culture polystyrene supports the expansion of pluripotent human embryonic stem cells (hESCs). Hammad et al. [66] used MS to investigate this effect by exposing untreated and plasma-treated surfaces to a complex mouse embryonic fibroblastconditioned cell culture medium. Among 71 proteins identified on both surfaces, 14 were shown to be uniquely adsorbed on plasmaetched polystyrene. Further validation using a combinatorial protein spotting approach showed that a combination of heat shock protein 90 and heat shock protein 1 promoted adherence of pluripotent stem cells to the surface.

Apart from surface roughness also the chemical properties of the biomaterial are important factors in determining the fate of the implant. Abdallah et al. [67] investigated this by using label-free liquid chromatography-electrospray ionization-tandem mass spectrometry (LC-ESI-MS/MS) to measure the proteomic signature of ECM proteins adsorbed on surfaces of widely used biomaterials including several types of hydrogels, metals, and polymers. While this study confirmed that both chemical and structural properties of the biomaterials affect the content of the adsorbed protein layer, a particularly interesting finding was that amination of poly(methylmetacrylate) (PMMA) and of poly(D, L lactic acid) (PDLLA) allowed the adsorption of important basal lamina proteins laminins $(\alpha, \beta)$, nidogen- 1 , and keratin 5 , which in turn resulted in improved adhesion and proliferation of epithelial cells. In contrast, phosphorylation of PDLLA and PMMA decreased the protein content of laminins $(\alpha, \beta)$, nidogen-1, and keratin 5 (Fig. 3).

Chemical modifications on titanium (Ti), commonly used in dental and orthopaedic applications owing to its mechanical properties and biocompatibility, have also been evaluated for their effect on protein adsorption [68]. For example, the properties of the
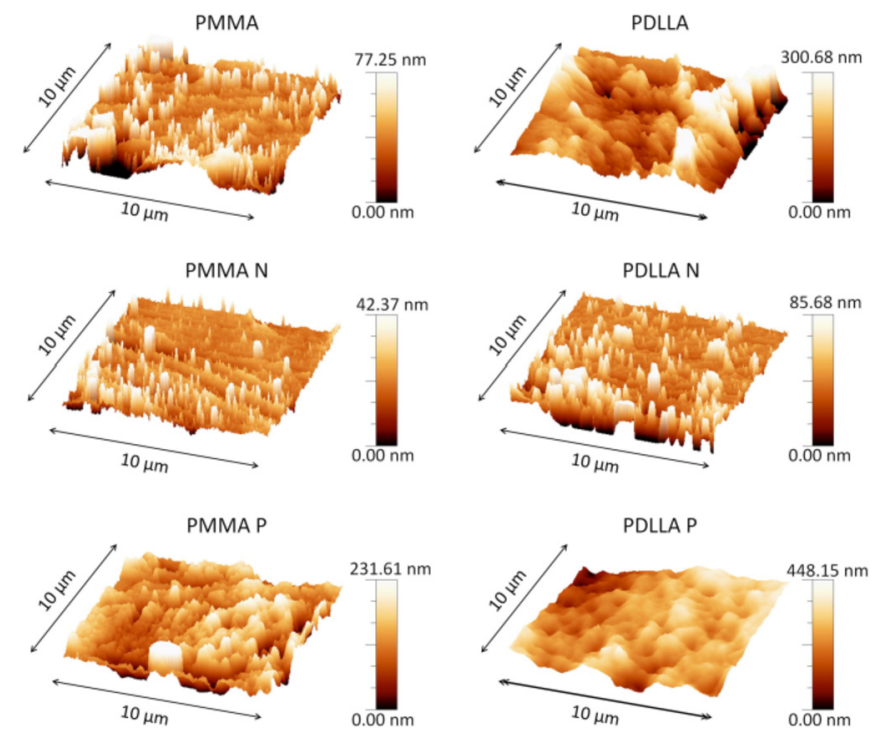

Fig. 3. Influence of chemical surface modifications on protein adsorption. Atomic force microscopy images showing amination (middle row) and phosphorylation (bottom row) of PMMA and PDLLA surfaces, which affected the adsorption of basal lamina proteins [67]. Reprinted, with permission from Abdallah et al. [67]. surface of Ti dental implants, consisting of titanium dioxide $\left(\mathrm{TiO}_{2}\right)$, are essential for osseointegration, which is defined by a direct contact of bone with the implan surface. This is partially attributed to the fact that $\mathrm{TiO}_{2}$ attracts proteins that are related to bone like proteoglycans, ECM proteins, enzymes, and growth factors [69] as well as proteins related to cell adhesion, transport, coagulation, immune response and cytokines [65]. However, in some, instead of direct bone-to-implant contact, a fibrous layer may be formed on the surface of these implant, eventually leading to implant failure [70]. In an attempt to improve osteointegration of Ti implants, Oughlis et al. [70] studied Ti implants coated with poly(sodium styrene sulfonate), using uncoated $\mathrm{Ti}$ as a control. Separation of eluted proteins by high-resolution 2-DE gel coupled to nano-LCMS/MS exhibited a significantly higher number of proteins adsorbed from platelet-rich plasma, leading to improved cell adhesion on polymer-functionalised Ti compared to control material. Similarly, Romero-Gavilána et al. [15] assessed protein adsorption on four types of hybrid sol-gel biomaterials based on different ratios of methyltrimethoxysilane, 3-glycidoxypropyl-trimethoxysilane tetraethyl orthosilicate and triethoxyvinylsilane silicates. These materials have been shown to enhance the bone regenerative capacity of calcium phosphate (CaP)-based materials by releasing osteoinductive silicon compounds [71]. Using LC-MS/MS they found six proteins related to complement pathway and acute inflammatory response that were more abundant on materials with a higher organic compound content and a more hydrophobic surface, which correlated with weaker biocompatibility. This data shows that distinct biomaterials properties such as hydrophobicity can affect the composition of the adsorbed proteins and determine the biocompatibility and bioactivity of biomaterials.

Similarly, Yang et al. [72] studied the role of adsorbed proteins on cell adhesion and cellular protein profile in response to two materials, nickel titanium (NiTi) alloy and titanium nitride (TiN) with the aim to evaluate the effect of nickel ion release on endothelial cell function. They found that in the early stage, the ion release did not affect cell adhesion mediated by the adsorbed proteins. The same authors used proteomics to examine the molecular mechanism behind the effect of adsorbed proteins on cell attachment using uncoated TiN, TiN coated with NiTi and chitosan films [73]. TiN and NiTi adsorbed significantly higher amounts of serum proteins related to cell adhesion and growth compared to chitosan films. The authors identified four mechanisms that mediated enhanced cell adhesion and proliferation on these materials; by adsorbed proteins that bound to cell surface receptors, by inducing the TGF- $\beta$ signalling pathway, by binding of adhesive glycoproteins that activate integrins, and lastly, by binding of proteins that regulate actin cytoskeleton organization.

In addition to chemical modifications, materials of the same chemical nature but differing in their chemical phase have been evaluated for their biological responses. A known example are CaPbased ceramics, widely used biomaterials in bone repair and regeneration owing to their close chemical resemblance to natural bone mineral. Different chemical phases of CaP impart different physicochemical properties such as grain size, specific surface area, and degradation, which in turn affect their in vivo biological performance. For example, when comparing octacalcium phosphate (OCP) and hydroxyapatite (HA), the former phase, which is more degradable than HA, was shown to better support bone formation [74]. In a study focusing on protein adsorption on these materials using LC-MS/MS, it was shown that more proteins from rat serum adsorbed on OCP than on HA [75]. Further quantification of target proteins showed significantly higher levels of apoliprotein E (ApoE), known to promote osteoblast differentiation in vitro, on OCP compared to HA. In contrast, complement 3 (C3), a crucial component of the innate immune system [76] and involved in 
osteoclast induction [77], was significantly upregulated on HA compared to OCP. These differences in protein adsorption were suggested to be a reason for the different biological performance of OCP and HA in terms of bone formation. For this study, multiple reaction monitoring (MRM) analysis was used, which consists of two stages of mass selection of the precursor ion, yielding a very specific and sensitive measurement of the target analyte in complex protein mixtures [78].

In a number of studies, proteomics-based analyses were used to study the biocompatibility of haemodialysis membranes [79]. For example, Urbani et al. [80] and Pieroni et al. [81], used label-free shotgun proteomic analyses to compare protein adsorption profiles between two types of membranes used in the extracorporeal haemodialysis systems. Protein analysis and coagulation profiles were performed on elutes from patients undergoing dialysis, either by using the cellulose triacetate or the synthetic polymer polysulfone-based helixone membrane. The results of these studies revealed differentially expressed proteins on the two membranes, with low abundant proteins predominantly found on the helixone membrane, and high-abundant plasma proteins more concentrated on the cellulose triacetate membrane. Furthermore, it was demonstrated that the coagulation biological pathways are modulated during dialysis. The differences between the two membranes were shown not to be patient-dependent, but rather membrane material properties dependent, with differences lying partially in their hydrophilicity.

The described approaches of investigating the effect of different physicochemical properties of biomaterials on protein modulation offer an improved understanding of the factors that influence protein adsorption on the surface and eventually cell behaviour. However, elucidating the exact mechanisms of how proteins are adsorbed on biomaterials is far from complete. Accurate, reliable, and high-throughput/high-content measurements are needed to further understand the protein adsorption phenomena, in combination with comprehensive characterisation of the material properties. An elegant example of a study in which protein adsorption was used as a tool to design new materials in search for optimised stem cell microenvironments is the study by Mei et al. [82]. Here, high-throughput polymer synthesis was coupled to a fast materialprotein-cell interaction assay, revealing that the chemical diversity of the materials led to different fibronectin adsorption and cell adhesion. The observed effect was attributed to the capacity of the polymers to induce different conformations of the adsorbed fibronectin.

\section{Protein production by cells on biomaterials}

Following the initial events of protein adsorption on the biomaterial surface, cells that are in contact with the biomaterial can attach, proliferate and differentiate. These processes are associated with unique protein production profiles, and describing these profiles is useful in understanding and steering cell-material interactions. Few examples of studies exist in which high-content protein analyses were successfully used to describe such processes in relation to physical, chemical or structural properties of biomaterials.

For example, in an effort to understand the biological effects of surface topography on cell behaviour, Kim et al. [27], determined protein production of osteosarcoma MG-63 cells cultured on Ti surfaces. Smooth (S), grit-blasted and acid-etched (SMA), and a surface coated with a thin layer of hydroxyapatite (HA) were used for cell culture, followed by two-dimensional gel electrophoresis and matrix assisted laser desorption ionization time of flight mass spectrometry (MALDI-ToF-MS) analysis. A lower proliferation rate was observed for cells cultured on rougher, SMA and HA-coated surfaces, compared to the S surface. Furthermore, SMA surfaces exhibited upregulation of protocadherin- $\beta 3$ precursor, kinase insert domain receptor, fibroblast growth factor receptor-3, and insulinlike growth factor I compared to S surface, whereas HA surface, compared to $S$ surface, showed upregulation of adhesion kinase, collagen $\alpha-1$ (I) chain precursor, collagen type XI $\alpha 2$, and cadherin11. All these proteins are known for their role in osteoblast adhesion, proliferation, differentiation and cell-cell contact. These findings demonstrated that different surface modifications of titanium triggered the production of different osteogenic proteins, which may explain, or even predict the clinical behaviour of these materials.

To unravel the mechanism behind the effect of nanosized surface structure with different organisation levels on cell fate, Kantawong et al. [83] studied the differentiation of osteoprogenitor cells towards osteoblasts on controlled disordered nanopit topographies on poly(caprolactone) films by employing differential in-gel electrophoresis (DIGE) and dimethyl-labelling proteomics. The results showed differences in the expression of proteins by the progenitor cells cultured on different surfaces, which resulted in the identification of the extracellular signal-regulated kinase (ERK1/2) pathway as the main pathway involved in the process of cell differentiation. This study elegantly demonstrated that examining protein expression and secretion profiles by cells can be useful in describing the correlation between individual material surface properties and biological responses to such materials.

In another study, Henrionnet et al. [84] used a label-free LCMALDI technique to perform relative quantification of secreted proteins in tissue-engineered cartilage constructs, consisting of human mesenchymal stem cells (hMSCs) undergoing chondrogenic differentiation inside collagen-based scaffolds. This study emphasised the potential power of secretome analysis as a noninvasive testing/validation tool for the quality of such tissueengineered constructs, but could also be used as an in vitro biomaterial evaluation tool.

Zhang et al. [85] investigated the interactions between natural HA ceramic, derived from porcine bones, and bone marrow-derived mouse MSCs by combining miRNA, transcriptomics and proteomics analyses, the latter labeling the samples with 8-plex iTRAQTM and employing 2D strong cationic exchange/reversed phase liquid chromatography matrix-assisted laser desorption/ionizationtandem mass spectrometry (SCX/RP-HPLC-ESI-MS/MS). This study delivered important insights in the regulation of mRNA protein pairs by a set of miRNAs in five different differentiation-related pathways. Furthermore, the study confirmed the role of the ERK1/2 and JNK MAPK pathways in the osteogenic differentiation of mMSCs, upon culture on the HA ceramic.

In a follow up study [86], the natural HA ceramic from the previous study was compared to a synthetic HA ceramic in a similar experimental set-up. Proteomics analysis following the culture of MSCs on the two ceramics revealed that the pathways associated with cell adhesion, proliferation and differentiation were regulated on both ceramic types, whereas the specific pathways related to ECM mineralization and angiogenesis were solely supported on the natural ceramic. The differences in the behaviour of cells were attributed to the differences between the two ceramic types, with the natural HA, but not synthetic HA, containing carbonate and hydrogen phosphate groups, and showing magnesium release and a more pronounced calcium release. Furthermore, the crystal size and the crystallinity of the natural ceramic were higher than that of its synthetic counterpart.

Taken together, although still limited in numbers, these studies demonstrate that the proteomics is a useful tool to describe the behaviour of cells on biomaterial surfaces, which, if combined with appropriate material design, can deliver insights in the relationship 
between material properties and a biological response. In turn, this knowledge can be used as an important input parameter for the design of new biomaterials with specific bioactivity.

\section{Proteomics to study safety and efficacy of nanomaterials and nanomaterials-based composites}

While the number of studies in which proteomics has been used to correlate the properties of materials to their biological performance is limited, such techniques are more prevalent for examining the biosafety and efficacy of nanomaterials, including nanoparticles. Due to their unique chemical and physical properties, nanoparticles represent one of the most promising tools for targeted drug delivery. However, a deeper understanding of the complex dynamics after their in vivo administration is required. Yang et al. [87] used proteomic approaches (by ESI MS/MS) to understand the difference in response between diseased (liver tumour cells, HepG2) and liver normal cells (CCL-13) upon chitosan nanoparticle exposure. The authors identified 6 unique proteins involved in cell growth, differentiation and cycle regulation that were upregulated in HepG 2 cells, but not in CCL-13 cells. These 6 proteins related to the PI3K/AKT1/mTOR pathway, which is involved in metastasis and proliferation of cancer cells [87].

Proteomics can also be a useful tool in understanding the effect of shape and size on the biological effect of nanoparticles [88,89]. This was elegantly demonstrated by Xu et al. [90], who monitored the proteome in osteoblast cells incubated with various nano-sized HA particles. Interestingly, they found that cells treated with spherical nano HA showed a higher migration rate compared to cells incubated with needle-shaped nano HA.

The in vivo stability, biodistribution and fate of nanoparticles has been found to be highly dependent on the formation of what is commonly referred to as the protein corona $[63,91]$; the spontaneous coating of nanoparticles surface with proteins in biological solutions. The role of this complex and dynamic layer of proteins on the biological activity of nanoparticles needs to be better understood before nanoparticles can reach their full clinical potential. Proteomics can be a useful tool to help identify this complex layer [92]. For example, Landgraf et al. [93] used SDS-PAGE coupled to label-free proteomic approach to analyse and compare the protein corona formation on PEGylated gold-iron(II,III) oxide based asymmetric Janus particles, to spherical PEGylated iron(II,III) oxide nanoparticles (both $\mathrm{NH} 2$-functionalized and non-functionalized). They observed that spherical NH2-functionalized iron(II,III) oxide nanoparticles had a higher binding affinity for coagulation factors compared to the other tested nanoparticles which may induce an immune response in vivo. Thus, spherical iron(II,III) oxide nanoparticles may be less favourable in drug delivery compared to functionalized asymmetric Janus particles. Knowledge on protein corona formation can also be used to functionalise nanoparticle surfaces to prevent or direct specific corona formation. For example, it has been found that the PEGylation ratio on the surface of gold nanoparticles can have a great influence on protein adsorption quantity and, in addition, the type of adsorbed proteins [94]. In this same study it was shown that higher PEGylation density on the gold nanoparticle surface resulted in less adsorbed proteins which in turn led to a less pronounced uptake by macrophages (Fig. 4).

While the above described studies function as examples of where proteomics can be a useful tool in studying nanoparticle safety and efficacy, for a more comprehensive overview, the reader is reffered to other excellent reviews on this topic [95-98].

More recently, nanoparticles have been used in the field of tissue and organ regeneration, by means of incorporating them inside other functional materials with the aim to enhance the properties

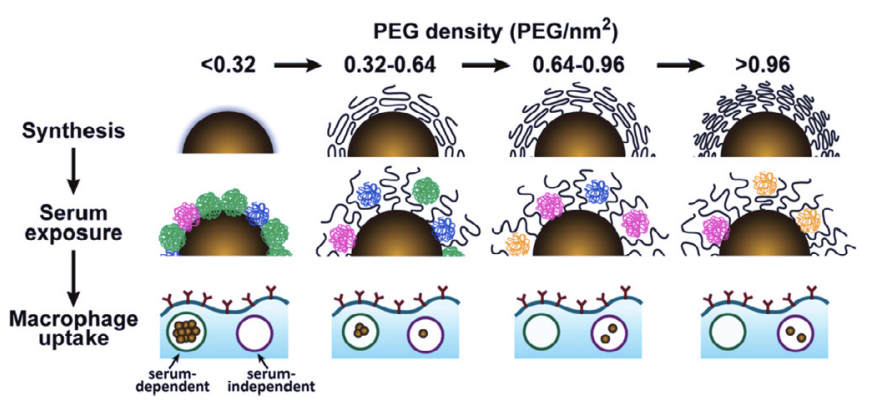

Fig. 4. Protein adsorption and uptake by macrophages of nanoparticles depend on the degree of poly(ethylene glycol) (PEG) surface modifications, a process known as "PEGylation". Higher PEG-density resulted in less protein adsorption and less efficient macrophage uptake. Low PEG-density modified nanoparticles led to lower protein adsorption and higher serum dependant macrophage uptake. Reprinted, with permission from Walkey et al. [94].

and bioactivity of these materials. In dentistry, for instance, $\mathrm{TiO}_{2}$ nanoparticles have been shown to increase the mechanical properties and to contribute to the antimicrobial effect of dental materials [99]. Gao et al. [100] investigated the early response of lymph node proteins to intradermal exposure to $\mathrm{TiO}_{2}$ nanoparticles in mice. By using trypsin-catalyzed 160/180 labelling in conjunction with 2D LC-MS/MS, the authors identified 33 differentially expressed proteins in samples exposed to $\mathrm{TiO}_{2}$ compared to vehicle particles. These proteins may be involved in immune response, and lipid and mRNA processing. In another similar study, Armand et al. [101] used whole proteome analysis to reveal the toxicity mechanism of chronic exposure of A549 epithelial alveolar cells to $\mathrm{TiO}_{2}$ nanoparticles. The results showed a change in abundance of 30 proteins involved in glucose metabolism, trafficking, gene expression, mitochondrial function, proteasome activity, and DNA damage response. It was furthermore noted that the cell cycle progression and proliferation of cells exposed to $\mathrm{TiO}_{2}$ were decreased. Zhao et al. [102] performed LC-MS/MS analysis of protein changes in MG63 osteosarcoma cells that incorporated Stable Isotope Labelling with Amino Acids in Cell Culture (SILAC), and were cultured on nanosized HA (nHA) added to poly(etheretherketone) (PEEK), a widely used polymer in orthopaedic surgery. The majority of upregulated proteins were involved in processes related to calcium ions, such as endocrine- and other factor-regulated calcium reabsorption, the calcium signalling pathway, calcium ion transmembrane transport, and sarcoplasmic reticulum calcium ion transport. The downregulated proteins were related to RNA processes such as spliceosome, the mRNA surveillance pathway, RNA transport, RNA splicing, and mRNA $3^{\prime}$-end processing. This study revealed that incorporating $n \mathrm{HA}$ into PEEK increased the bioactivity of the composites and demonstrated the suitability of a proteomics approach in monitoring global protein expression. In a similar approach, Jinling Xu et al. [103] compared protein profile changes in osteoblasts cultured on HA and HA reinforced with carbon nanotubes (CNTs) using isobaric tags for relative and absolute quantification (iTRAQ) coupled to 2D LC-MS/MS analysis. The results revealed higher expression of cytoskeletal proteins, metabolic enzymes, signalling, and cell growth proteins in cells cultured on HA compared to CNT-HA.

These studies demonstrated the utility of proteomics approaches in evaluating cellular responses to new materials, specifically those incorporating nanoparticles. The rapid development of nanotechnology has resulted in the production of many different types of nanoparticles for various biomedical applications. The incorporation of nanoparticles into functional biomaterials for regenerative medicine can enhance the biological performance and properties of such materials [104]. As MS-based proteomics 
becomes more sensitive and reliable [36], this method could be used as an initial screening tool to compare different new nanomaterials and could become an excellent readout tool to monitor cellular responses.

\section{Proteomics to analyse ECM and ECM-derived products and their interactions with cells}

Various types of instructive biomaterials are currently under development for use in regenerative medicine applications. Biomaterials based on (mimics of) ECM are highly promising for their ability to reconstitute the natural in vivo microenvironment of cells, supporting them in accomplishing the process of repair and regeneration [105]. ECM-based approaches have known several successes in replacing and treating damaged tissues like tendon, muscle, heart valves, bone, and cartilage [106,107]. The widespread use of ECM is related to their structure and protein content, which are determinant for the performance of ECM in (re)creating the optimal microenvironment for cells. It is therefore not surprising that an extensive range of proteomics studies have focused on describing the exact content of ECM and ECM-derived products. Understanding this content, and the role of individual proteins in the matrix, is particularly important since currently, the majority of ECM-based materials result from a decellularisation process of natural tissues or organs, which is why they are highly heterogeneous and often differ from batch to batch.

Matrigel is probably the most widely used ECM-like biomaterial, in particular in cancer and stem cell research. Matrigel is composed of a complex mixture of basement membrane proteins and has the unique ability to maintain stem cells in the undifferentiated state [108]. In an attempt to describe its contents, Hughes et al. [109], analysed and compared standard Matrigel and growth factor-reduced (GFR) Matrigel. GFR Matrigel is derived from standard Matrigel but reduced in growth factors such as basic fibroblast growth factor, epidermal growth factor, insulin-like growth factor 1, transforming growth factor beta, platelet-derived growth factor, and nerve growth factor. By applying LC-MS after the two-step ammonium sulphate precipitation and size exclusion chromography (SEC), the authors were able to identify 1302 proteins in standard Matrigel, of which 480 were unique proteins (i.e., not found in GFR Matrigel). On GFR Matrigel, 1246 proteins (424 unique proteins not found in standard Matrigel) were detected. This approach provided insight into the complex protein content within different formulations of Matrigel, and suggested that, because of this complexity, replacing Matrigel by a synthetic matrix will be challenging.

Another ECM-based material that is often used for different applications including peripheral nerve, spinal cord, skin, and bone regeneration are keratose-based scaffolds. Keratose is an oxidized variant of human hair protein, keratin. Guzman et al. [110] employed MS to identify the exact protein content of keratose after oxidizing the cortical and cuticle parts of human hair. The MS results of the keratose extraction identified the abundance of cortical keratin species of type 1 (K31, 33A, 33B, 34, and 35) and type II (K81, 83, 85, and 86 ). In addition, $\mathrm{K} 1$ epithelial keratin was detected at very low concentrations. Characterisation of keratin and keratose, and understanding the role of their constituents is important for further optimisation of products based on these ECMs. For example, it has been shown that the manipulation of molecular weight, oxidative state, and effective crosslink density of these products may affect their degradation rate in vivo [6], however, these changes may also affect their protein content, in turn possibly changing the regenerative potential of the keratose-based products.

While several ECM products are commercially available, extensive research efforts are expended to develop new ECMs, by decellularising tissues and organs. Proteomics is a valuable tool to analyse the results of decellularisation and validate new protocols, supporting the development of new materials. For example, proteomics techniques have been used to demonstrate the effectiveness of decellularisation protocols of heart and lung tissues [111-113]. In contrast to these protocols, the existing methods were shown not to be suitable for removing chondrocytes from cartilage tissue, without modifying the composition of ECM, consisting of high-abundance proteins like collagens, proteoglycans, and hyaluronic acid, as well as low-abundance proteins including cartilage oligomeric matrix protein, fibromodulin, and fibronectin $[114,115]$. To address this challenge, Hsueh et al. [116] developed a novel cartilage ECM extraction method that allows subsequent proteomics analysis, demonstrating that MS-based proteomics can be used as a reliable tool for localising proteins within a cartilage matrix. The authors combined the conventional guanidine- $\mathrm{HCl}$ extraction method with in situ trypsin digestion, to preserve the ECM content and enable the analysis of the spatial distribution of proteins within the matrix, which may be used to study the progression of osteoarthritis (Fig. 5). The study demonstrated that the surface layers exhibited a more pronounced presence of both unique and abundant ECM proteins compared to deeper cartilage layers, while the deeper layers exclusively exhibited a few proteins including aggrecan core protein, fibroblast growth factor-binding protein 2 (FGFP2), and phospholipase A2 (PA2GA).

Calle et al. [117], employed LC-MS/MS to evaluate the protein content of lung ECM prepared using two methods of decellularisation and compared it with native tissue. They showed that by gentle decellularisation, proteins such as laminins, proteoglycans, and other basement membrane and ECM-associated proteins were preserved at a level closer to that of native tissue than when harsher conditions were used (i.e. CHAPs method, $0.4 \%$ solution of $\mathrm{pH}>12$ ). This study aided the optimisation of the decellularisation protocol, aiming at maximal preservation of the protein content, and in particular the growth factors content of the tissue, which is essential for maintaining bioactivity of the ECM.

In another study investigating the protein content of rat lung tissue [118], LC-MS/MS analysis was used to compare the native and decellularised ECM by examining both soluble and insoluble proteins and by using stable isotope-labelled peptides for endogenous protein quantification. The protocol used in this study, which was

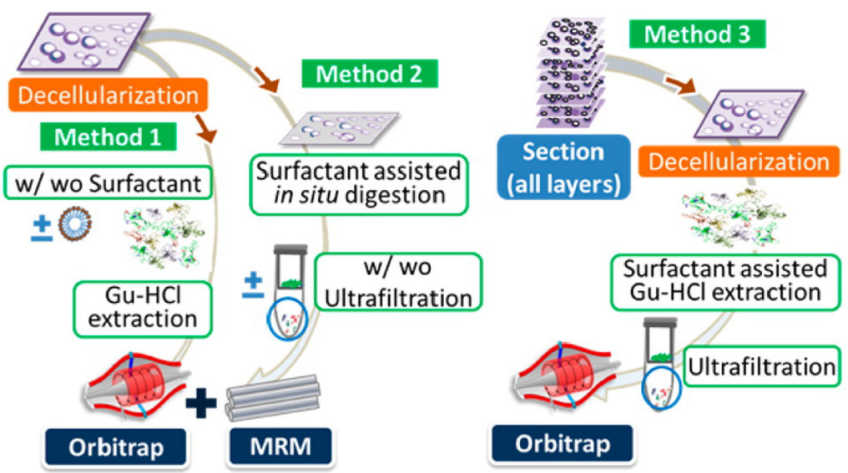

Fig. 5. Schematic illustrating the methodology used for preparing cartilage sections, to allow proteomic analysis. The sections were decellularised by a single freeze/thaw cycle in hypotonic solution. Method 1 illustrates the extraction of cartilage proteins by using guanidine-HCL extraction buffer with or without surfactant. Method 2 represents extraction of decellularised section by in situ trypsin digestion. Method 3 shows cartilage extraction by surfactant-assisted guanidine- $\mathrm{HCl}$ with ultrafiltration. The sections were collected from different cartilage layers (i.e., superficial, intermediate, and deep) of different joints and under different physiological conditions. All methods allowed subsequent qualitative and quantitative proteomic analysis. Reprinted, with permission from Hsueh et al. [116]. 
shown to be more accurate that the conventionally used methods, indicated that structural collagen was predominately found in the insoluble protein fraction in decellularised tissue and that the decellularisation method eliminated $98 \%$ of the intracellular proteins.

While the global overview of the protein content of an ECM may be sufficient in some applications, in other cases, monitoring the presence of a specific protein or growth factor is of great importance. In a study by Nienhuijs et al. [119], the biological content of COLLOSS ${ }^{\circledR} \mathrm{E}$, an equine derived ECM consisting of a collagenous matrix and a growth factor mixture, was investigated using ELISA, Western blot, and LC-MS/MS. The rationale behind this study was to identify which growth factors are present in COLLOSS ${ }^{\mathbb{R}} \mathrm{E}$ and relate these to its osteoinductive capability. Interestingly, ELISA identified BMP-2 and BMP-7, which were not detected by either MS or Western blot. LC-MS/MS identified a number of growth factors, including TGF- $\beta 1$, TGF- $\beta 2$, and BMP-3. These findings were validated by the Western blot analysis except for BMP-3, which could not be identified using this method. It was furthermore suggested that $\operatorname{COLLOSS}{ }^{\circledR} \mathrm{E}$ possibly contains more proteins that were not detectable by the three techniques used. This study shows that, while useful in determining the global composition of ECM and related proteins, there is still room for improvement when it comes to identification of individual, low-abundance proteins, even when different (high-throughput and high-content) techniques are used. Some of these technical issues can be overcome by for example, sample fractioning to reduce sample complexity, frequent preclearing, and using high-mass resolution instrumentation to identify low-abundant proteins [36].

While a majority of studies on ECM-like biomaterials focused on understanding the content of different matrices, several studies exist in which the interactions between cells and ECMs were investigated to identify which components of the materials are responsible for specific biological responses. For example, Hughes and coworkers [120] performed a proteomic analysis employing strong anion and strong cation exchange chromatography and SDSPAGE, to identify the composition of five commonly used ECMs, and Matrigel. The authors identified fibronectin as being critical for maintaining pluripotent $\mathrm{H} 9$ and CA1 hESCs in an undifferentiated state, which is a step forward to designing new, and better defined ECM products.

Similarly, Soteriou et al. [121] employed proteomics to characterise and catalogue a range of ECMs that are supportive for selfrenewal of hESCs. This study further revealed that it is a balance between structural network properties and molecular composition of ECM and protein-to-protein interactions that determines the maintenance of pluripotency of hESCs.

In another study [122], LC-MS/MS was used to analyse the contents of three types of ECMs generated from decellularised undifferentiated ESC aggregates, spontaneously differentiated embryoid bodies and the ESC-derived neural progenitor cell aggregates. Following this analysis, the capacities of these different ECMs to support proliferation and neural differentiation of mESCs and human induced pluripotent stem cells (hIPSCs) were investigated. Interestingly, the cells cultured on different ECMs showed distinct cellular phenotypes, with undifferentiated ESC-derived ECM supporting the maintenance of pluripotency and the neural progenitor cell derived ECM supporting neural differentiation.

The studies described in this section exemplify the possibilities that the proteomic approaches offer for obtaining a deeper understanding of the composition of ECM and ECM-derived products, as well as for getting insight in interactions between such products and cells. This knowledge is essential for assessing the suitability of ECM products for various biomedical applications. Furthermore, the complete understanding of the contents of matrices such as
Matrigel and the role/relevance of each of its constituents in the biological response to this matrix, will pave the way towards successful synthesis of fully synthetic ECM products.

\section{Discussion}

In this review, we focused on the current knowledge of the role proteins play in interactions between biomaterials used in biomedical applications and biological systems. The aim was to understand how this knowledge can be used for developing new biomaterials with improved performance and for a faster and more efficient translation of the research results to the clinic. Emphasis was placed on high-throughput and high-content methods for protein analyses, mainly MS, as such methods are particularly useful for obtaining a complete understanding of these interactions.

Not surprisingly, the majority of studies investigated the adsorption of proteins on biomaterials surfaces, the very first event in the interaction between biomaterials and a biological environment. The ability to control the process of protein adsorption, either by facilitating selective binding of desired proteins, or by preventing binding of undesired ones, is determinant for the fate of the material upon implantation, and its performance. This does not only concern the inflammatory response of the body to the material, but also the processes leading to tissue repair and regeneration, such as cell adhesion, proliferation and differentiation. Nevertheless, very few studies exist in which biomaterials design was actually used to control protein adsorption and consequent extracellular environment [82]. A vast majority of studies is still at the stage of identifying proteins adsorbed to the existing biomaterials, and describing the process of adsorption. This concerns both the materials already used in the clinic, such as membranes for dialysis [80,81], Ti implants widely used in orthopaedics [69,123] and extensively applied polymers such as PMMA and PDLLA [67], to new biomaterials designs. All these studies have shown that both the environmental effects, as well as the properties of the biomaterials themselves, such as chemical composition, topography, surface charge, etc. have an influence on (selective) adsorption of proteins from biological fluids. Nevertheless, because of a large variety in materials and experimental set-ups used, it is difficult to make a direct comparison among different studies, and to define the correlation between biomaterial properties and protein adsorption.

Similar to protein adsorption, different material properties were also shown to affect the interactions between cells and biomaterials at the protein level. These studies often focused on understanding the fate of cells in contact with biomaterials surfaces, it terms of differentiation and ECM production. Some of these studies have delivered important insights in, for example, pathways leading to nanotopography-triggered differentiation of osteoprogenitor cells into the osteogenic lineage [83]. Interestingly, this specific study made use of carefully designed materials, without immediate relevance for the clinical use, and was performed in a highly controlled experimental set-up. This shows that, in order to get mechanistic insights, one may need to use a bottom-up research approach starting with model materials, with highly controlled properties and then progress to other functional materials, to test whether similar mechanism are also valid in a more complex environment.

Proteomic approaches were also used in studies focusing on understanding safety and efficacy of nanoparticles. Such studies have shown that proteomics analyses were useful in describing protein corona and have delivered important insights in global biological responses to nanoparticles, including immune response, cell cycle and cell proliferation, apoptosis, and cellular adhesion. It 
is envisioned that the use of nanoparticles in regenerative medicine will further increase in the future, leaving much space for MS-based proteomics techniques to be used to study their long-term performance as well.

At least as important as the design of functional implant biomaterials and nanoparticles for regenerative medicine is the rational design of (synthetic) alternatives to ECM products like Matrigel, which, owing to their natural origin, often suffer from batch-to-batch variability. This in turn can tremendously affect their performance in (re)creating cellular microenvironments, e.g. in organoids, which are increasingly important for regenerative medicine applications. MS-based techniques have been shown to be particularly useful in identifying the contents of ECM and ECMderived products $[109,110]$ as well as to develop new methods for developing ECM products, e.g. by evaluating the efficacy of decellularisation procedures [117,118]. Furthermore, few elegant studies have shown the effect of the ECM constituents on cell behaviour [121], which is a step forward in the design of synthetic ECM alternatives.

Although this review proves that proteomic techniques have vastly contributed to the existing knowledge of interaction between biomaterials and cells/tissues, it remains difficult to draw general conclusions regarding the effects of biomaterial properties on protein adsorption or production, for several reasons. First, the process of protein adsorption and subsequent process of cell attachment, differentiation, and ECM formation are affected not by one, but by several properties of a material. In most functional, clinically used materials, such properties are intertwined, meaning that it is difficult to change one property without affecting the others. In other words, from a biomaterials perspective, it is very difficult to parameterise individual properties in order to get deeper insights into their correlation with a biological response. Second, most studies are performed on a limited set of (new) materials, the properties or the clinical performance of which are not (yet) fully known. As a result, such studies remain observational rather than mechanistic, describing differentially adsorbed or secreted proteins on surface one versus surface two, but not giving a biological meaning to this interaction. Finally, since techniques for proteomic analyses are also evolving, no consensus exists yet regarding the best method to study proteins on biomaterials, making it difficult to make comparisons among individual studies. For example, the majority of studies discussed in this review have employed data-dependent acquisition (DDA) methods $[101,124,125]$. DDA uses knowledge obtained during the acquisition to decide what MS1 peptide precursors to subject for fragmentation (MS/MS) in the collision cell. Data-independent acquisition (DIA), in contrast, performs predefined MS/MS fragmentation and data collection regardless of sample content, which allows for more sensitive and accurate protein quantification compared to DDA [126].

To overcome the existing challenges, and obtain a better understanding of cell-material and tissue-material interactions that can aid the design of new biomaterials and their more effective translation to the clinic, changes in experimental designs are required. For example, a thorough characterisation of as many properties of the tested materials as possible would enable a better comparison among individual studies. In this context, using benchmark materials as controls in studies where new materials are investigated would be useful in relating the observed effect to the final clinical performance. Furthermore, to be able to establish better property-function relationships, it is important to invest in methods that allow decoupling of individual properties of functional biomaterials [127]. In a few recent elegant reviews and studies, parameterisation of individual material properties coupled with a description of the genomics, transcriptomics, miRNA sequencing and proteomics landscape of their biological effects, was suggested as a useful tool to understand interactions of biomaterials with a biological system $[43,85,95,128]$. Only when such tools become routinely used in the biomaterials research, will the field get full benefit from the results of proteomic studies. It is furthermore important that the implementation of this tool is done in close collaborations with people advancing the proteomics, and other-omics techniques, to identify the best option for answering individual research questions.

Regardless of the exact application, the use of MS-based proteomics to study biomaterial-cell interactions requires expertise in sample preparation and analysis as well as data processing, to ensure that reliable and meaningful results are obtained. Furthermore, it is important to understand the limitations and the pitfalls of each of these steps as well as of the specific MS technique when designing the experiments [36]. Clearly, MS has the potential to be much more broadly exploited as a means to obtain a more comprehensive understanding of cell-biomaterial and tissue-biomaterial interactions, serving as input for the design of new biomaterials and their more rapid implementation in the clinic.

\section{Outlook: possibilities of mass spectrometry imaging (MSI) in understanding interactions between biomaterials and biological systems}

Among various technological advancements in the field of proteomics, mass spectrometry imaging (MSI) (Fig. 6) will be highlighted here as a method that offers new possibilities for a better understanding of interactions between biomaterials and biological systems, that go beyond state of the art. With MSI, mass spectrometry data is acquired from thin sample sections in a spatially resolved manner. Images that represent the distribution of the analytes within the sample are then generated [129]. MSI can offer spatial molecular information at submicrometer level and reveal specific zonal molecular profiles that cannot be studied by conventional histological methods, most of them targeted. MSI technology is able to assess complex molecular mixtures in cells and tissues with high chemical specificity, allowing simultaneous analysis of a variety of molecular species in a wide mass range, from small metabolites to large macromolecules such as proteins. Further structural assessment of compounds, employs high mass accuracy by FT-ICR or orbitrap technology and MS/MS fragmentation analysis [130].

Among the different MSI ionisation technologies, secondary ion mass spectrometry (SIMS) and MALDI are probably the most applicable to the field of biomaterials. With SIMS, detectable ions are typically limited to a narrow mass range of only a few hundred Daltons but can achieve a spatial resolution down to $100 \mathrm{~nm}$ with the capabilities recently offered [131]. Cluster ion sources (e.g., $\mathrm{C} 60+$ and $\mathrm{Bi} 3+$ ) have effectively extended this mass range limit to $\sim 2$ kDa [132]. The majority of the studies have focused on drugs, lipids, and elemental distribution in the field of surface material characterisation. For example, time-of-flight (ToF)-SIMS has been used to describe lipid profiles of stem cells after chondrogenic induction as well under different oxygen tensions in order to characterise markers of cartilage formation [133]. Using ToF-SIMS, Henss et al. spatially resolved the calcium and collagen distribution in bone to assess the quality of the interface of bone implants with a lateral resolution up to $1 \mu \mathrm{m}$ [134]. The method has been also employed to study HA formation at the interface between bone and Ti implants [135]. Although ToF-SIMS images contain a large array of data related to the distribution of chemical species on a surface, processing these data to obtain chemical information is not trivial. As a result, multivariate statistical methods have proven to be 
A

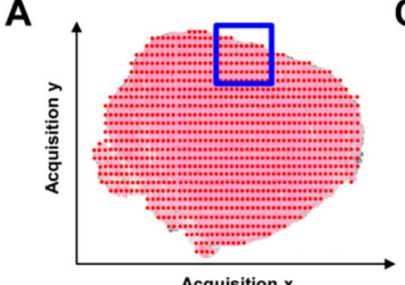

C

B

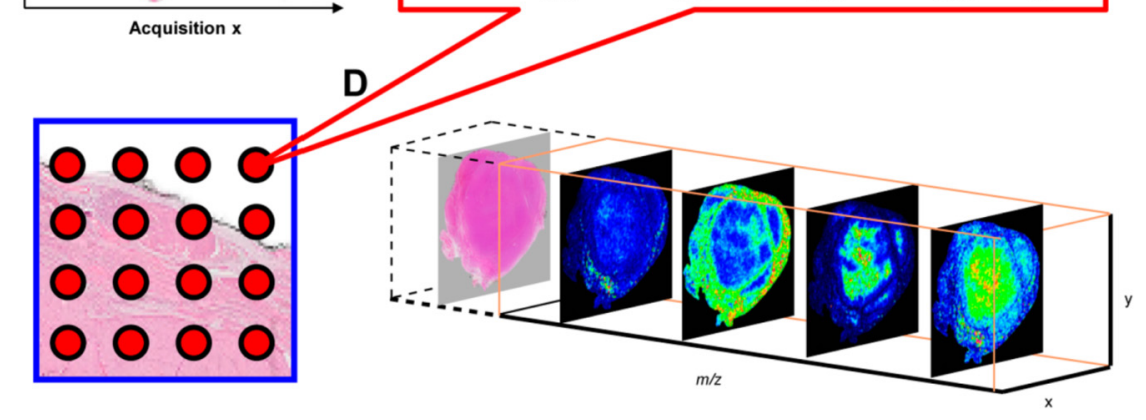

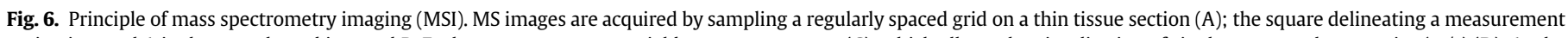

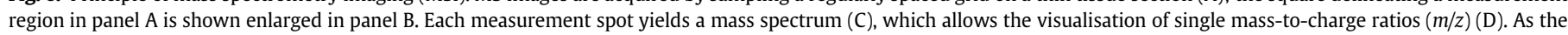
sample stays intact, coregistration of the sample histology with the MSI images is possible (D) Reprinted, with permission from Addie et al. [129].

highly valuable [136]. For example, Wagner et al. have employed ToF-SIMS coupled to multivariate analysis, in particular, principal component analysis, to characterise adsorbed protein films on surfaces of biomaterials such as mica, poly(tetrafluoroethylene), and silicon wafer [137]. The interpretation of the spectra of proteins such as fibronectin, collagen, and three fibronectin-collagen mixtures, adsorbed on smooth silicon substrate has been possible following this workflow [138]. The use of ToF-SIMS with other methods, such as Raman spectroscopy, and in combination with multivariate analysis, permits identifying the fate decisions of individual cells with location specificity. This combination enables the characterisation of surface chemistry on biomaterial surfaces, which is critical for understanding the biointerfacial interactions that modulate cell response [139]. As mentioned above, the study of proteins and peptides with ToF-SIMS is challenging. Recent work from our group has shown the capabilities of tandem matrixenhanced (ME)-SIMS for de novo sequencing of endogenous peptides from rat pituitary gland tissue. As such, ME-SIMS has overcome one of the biggest disadvantages of SIMS analysis by providing the ability to detect biomolecules at high spatial resolution, now including peptides [140].

Compared to SIMS, MALDI imaging can be used for analysing peptides and proteins up to $\sim 100 \mathrm{kDa}$ [141]. In this approach, tissue/ material sections are covered with a matrix (typically a small organic acid) for extracting molecules from the specimen and allowing desorption/ionisation for further analysis in the mass spectrometer. For the ionisation process, the laser ablates the matrix layer, while the underlying specimen remains intact and thus allowing histological examination after the MS measurement. The matrix absorbs the laser energy and transfers the analytes to the gas phase. The specimen is then raster-scanned (with spatial resolutions down to $\sim 3 \mu \mathrm{m}$ nowadays [142-144]), generating a mass spectrum for each measured spot [132]. Key parameters to obtain high spatial resolution images are mainly 1 ) the choice of matrix and its application (i. e. choosing an appropriate matrix for analytes of interest and homogeneity when applied to the tissues) and 2) the laser spot size [144]. In the field of biomaterials, MALDI imaging has been employed in combination with gel electrophoresis and thinlayer chromatography to compare the biological adsorption and lipid and protein diffusion occurring with expanded poly(tetrafluorethylene) (ePTFE) and thermoplastic poly(urethanes) (TPU), both used for blood vessel reconstruction [145]. This study demonstrated an interaction between biological and graft materials, and provided insights into polymer changes as early as $10 \mathrm{~min}$ after in vivo exposure.

The technology typically used for protein MSI, is a ToF mass spectrometer equipped with a micro-channel plate (MCP) detector, which is not well-suited to the detection of high $\mathrm{m} / \mathrm{z}$ ions. Lower mass ions can saturate the detector leading to even lower detection efficiencies for higher-mass ions. The use of other detectors or specific sample preparation methods with organic solvents, Triton $\mathrm{X}-100$ or ferulic acid, improves the detection of higher-mass proteins (up to $135 \mathrm{kDa}$ ) since they are not efficiently solubilised in the matrix solution and consequently, are not extracted from the tissue [101]. In situ enzymatic digestion can as well overcome the difficulties of intact protein analysis. This method consists of depositing trypsin solution onto a sample surface, which digests the proteins into peptides that can then be analysed [146]. This is especially relevant to assess the protein content of areas rich in ECM given its complex nature. Nevertheless, the tissue ion suppression and the lack of analyte separation, yield a very limited number of proteins identified in each position. Different combinations of enzymes can be used in order to improve the unravelling of the proteome. For example, hydrogel discs as carriers for the enzyme have been employed, thus allowing the digestion to take place directly on discrete tissue areas, preserving the relationship between molecular information and tissue architecture to analyse mineralised and non-mineralised areas of skin biopsies [147]. High resolution and accurate mass (HRAM) MALDI Orbitrap, combined with DDA tandem MS analysis, enables the division of entire $m / z$ into multiple segments of $m / z$ sub-ranges for MS interrogation. As a result, the complexity of molecular species from tissue samples and the heterogeneity of the distribution and variation of intensities of $\mathrm{m} / \mathrm{z}$ peaks are greatly decreased. By carefully optimising the experimental conditions such as the dynamic exclusion, the multiplexDDA-MSI approach demonstrates better performance with broader precursor coverage, less biased MS/MS scans towards high abundance molecules and improved quality of tandem mass spectra for low intensity molecular species [148].

The majority of MS methods described so far are performed in vacuum conditions, which can be challenging for some samples. Desorption electrospray ionisation (DESI) is an ambient MS 
technique in which a spray of ionised solvent is focused onto a surface and the desorbed molecules are collected and detected within the mass spectrometer. While this method has proven to be successful in analysing small molecules, it has been shown to be more challenging to adapt the technique for the analysis of proteins [149]. Another ambient technique, liquid extraction surface analysis (LESA), extracts analytes directly from a surface $(0.4-1.0 \mathrm{~mm}$ diameter) via the maintenance of a liquid/surface microjunction, which is the limiting factor in terms of lateral resolution. Rao et al. [150] have employed both methods coupled with in situ surface tryptic digestion to identify protein species from a material surface such as Permanox. This work presents a promising proof of concept for the use of ambient MS in the rapid and automated analysis of surface proteins [150]. The possibility of coupling a LC analytic separation step to the LESA platform, thus adding another dimension for peptide separation, could overcome some of the challenges presented by MSI and increase the number of protein identifications. Finally, it has been recently shown that atmospheric pressure MALDI-MSI enables the same tissue section to be first analysed by MSI, to identify regions of interest that exhibit distinct molecular signatures, followed by localized proteomics analysis using laser capture microdissection isolation and LC-MS/MS, thereby increasing tremendously the number of identifications [151].

The examples described in this section clearly demonstrate that MSI is potentially a highly valuable technique, which can bring new insights in the material-biological system interactions. Nevertheless, this technique is still far from routine use in the biomaterials research because of the specific sample preparation and treatment it requires, which is not always possible to perform on commonly studied and used biomaterials. Moreover, the throughput of this technique is low, and only a small number of samples can be studied in a reasonable amount of time, in contrast to other, more conventional proteomics techniques.

\section{Conclusions}

Taken together, this review has shown that the analysis of proteins is a highly valuable tool for understanding the interactions between biomaterials and biological systems. High-throughput and high-content methods, such as MS-based proteomics, have the potential to accelerate and advance our understanding of these interactions, despite technical challenges that need to be addressed. Furthermore, it is imperative to couple protein analyses to thorough material characterisation, to obtain fundamental insights in property-function relationships. Finally, novel techniques, such as MSI, will complement these insights by providing spatial molecular information about the interactions between materials and biological systems.

\section{Acknowledgements}

ZO acknowledges financial support by the Netherlands Science Organisation TA-COAST grant \# 05321104. This research has been in part made possible with the support of the Dutch Province of Limburg as part of the "LINK" program. We gratefully acknowledge the financial support by the Ministry of Education, Culture and Science (Gravitation Program 024.003.013). The authors declare no conflict of interest.

\section{References}

[1] B.M. Holzapfel, J.C. Reichert, J.-T. Schantz, U. Gbureck, L. Rackwitz, U. Nöth F. Jakob, M. Rudert, J. Groll, D.W. Hutmacher, How smart do biomaterials need to be? A translational science and clinical point of view, Adv. Drug Deliv. Rev. 65 (2013) 581-603, https://doi.org/10.1016/j.addr.2012.07.009.

[2] S.C.G. Leeuwenburgh, J.A. Jansen, J. Malda, W.A. Dhert, J. Rouwkema, C.A. van
Blitterswijk, C.J. Kirkpatrick, D.F. Williams, Trends in biomaterials research: an analysis of the scientific programme of the world biomaterials congress 2008, Biomaterials 29 (2008) 3047-3052, https://doi.org/10.1016/ j.biomaterials.2008.04.032.

[3] B.D. Ratner, S.J. Bryant, Biomaterials: where we have been and where we are going, Annu. Rev. Biomed. Eng. 6 (2004) 41-75, https://doi.org/10.1146/ annurev.bioeng.6.040803.140027.

[4] N. Huebsch, D.J. Mooney, Inspiration and application in the evolution of biomaterials, Nature 462 (2009) 426-432, https://doi.org/10.1038/ nature08601.

[5] I. El Bialy, W. Jiskoot, M. Reza Nejadnik, Formulation, delivery and stability of bone morphogenetic proteins for effective bone regeneration, Pharm. Res. (2017) 1-19, https://doi.org/10.1007/s11095-017-2147-x.

[6] R.C. de Guzman, J.M. Saul, M.D. Ellenburg, M.R. Merrill, H.B. Coan, T.L. Smith, M.E. Van Dyke, Bone regeneration with BMP-2 delivered from keratose scaffolds, Biomaterials 34 (2013) 1644-1656, https://doi.org/10.1016/ j.biomaterials.2012.11.002.

[7] A.W. James, G. LaChaud, J. Shen, G. Asatrian, V. Nguyen, X. Zhang, K. Ting, C. Soo, A review of the clinical side effects of bone morphogenetic protein-2, Tissue Eng. Part B Rev. 22 (2016) 284-297, https://doi.org/10.1089/ ten.teb.2015.0357.

[8] H. Yuan, H. Fernandes, P. Habibovic, J. de Boer, A.M.C. Barradas, A. de Ruiter, W.R. Walsh, C.A. van Blitterswijk, J.D. de Bruijn, Osteoinductive ceramics as a synthetic alternative to autologous bone grafting, Proc. Natl. Acad. Sci. U. S. A. 107 (2010) 13614-13619, https://doi.org/10.1073/pnas.1003600107.

[9] B.M. Holzapfel, J.C. Reichert, J.T. Schantz, U. Gbureck, L. Rackwitz, U. Nöth, F. Jakob, M. Rudert, J. Groll, D.W. Hutmacher, How smart do biomaterials need to be? A translational science and clinical point of view, Adv. Drug Deliv. Rev. 65 (2013) 581-603, https://doi.org/10.1016/j.addr.2012.07.009.

[10] N.J. Chang, C.C. Lin, M.Y. Shie, M.L. Yeh, C.F. Li, P.I. Liang, K.W. Lee, P.H. Shen, C.J. Chu, Positive effects of cell-free porous PLGA implants and early loading exercise on hyaline cartilage regeneration in rabbits, Acta Biomater. 28 (2015) 128-137, https://doi.org/10.1016/j.actbio.2015.09.026.

[11] K. Uematsu, K. Hattori, Y. Ishimoto, J. Yamauchi, T. Habata, Y. Takakura H. Ohgushi, T. Fukuchi, M. Sato, Cartilage regeneration using mesenchymal stem cells and a three-dimensional poly-lactic-glycolic acid (PLGA) scaffold, Biomaterials 26 (2005) 4273-4279, https://doi.org/10.1016/ j.biomaterials.2004.10.037.

[12] J. Kluin, H. Talacua, A.I.P.M. Smits, M.Y. Emmert, M.C.P. Brugmans, E.S. Fioretta, P.E. Dijkman, S.H.M. Söntjens, R. Duijvelshoff, S. Dekker, M.W.J.T. Janssen-van den Broek, V. Lintas, A. Vink, S.P. Hoerstrup, H.M. Janssen, P.Y.W. Dankers, F.P.T. Baaijens, C.V.C. Bouten, In situ heart valve tissue engineering using a bioresorbable elastomeric implant - from material design to 12 months follow-up in sheep, Biomaterials 125 (2017) 101-117, https://doi.org/10.1016/j.biomaterials.2017.02.007.

[13] P. Habibovic, H. Yuan, M. Van Den Doel, T.M. Sees, C.A. Van Blitterswijk, K. De Groot, Relevance of Osteoinductive Biomaterials in Critical-sized Orthotopic Defect, 2006, pp. 867-876, https://doi.org/10.1002/jor.

[14] G. Hulsart-Billström, J.I. Dawson, S. Hofmann, R. Müller, M.J. Stoddart, M. Alini, H. Redl, A. El Haj, R. Brown, V. Salih, J. Hilborn, S. Larsson, R.O.C. Oreffo, A surprisingly poor correlation between in vitro and in vivo testing of biomaterials for bone regeneration: results of a multicentre analysis, Eur. Cells Mater. 31 (2016) 312-322, https://doi.org/10.22203/ eCM.v031a20.

[15] F. Romero-Gavilan, A.M. Sánchez-Pérez, N. Araújo-Gomes, M. Azkargorta, I. Iloro, F. Elortza, M. Gurruchaga, I. Goñi, J. Suay, Proteomic analysis of silica hybrid sol-gel coatings: a potential tool for predicting the biocompatibility of implants in vivo, Biofouling 33 (2017) 676-689, https://doi.org/10.1080/ 08927014.2017.1356289.

[16] W.M. Gallagher, I. Lynch, L.T. Allen, I. Miller, S.C. Penney, D.P. O'Connor, S. Pennington, A.K. Keenan, K.A. Dawson, Molecular basis of cell-biomaterial interaction: insights gained from transcriptomic and proteomic studies, Biomaterials 27 (2006) 5871-5882, https://doi.org/10.1016/ j.biomaterials.2006.07.040.

[17] N. Araújo-Gomes, F. Romero-Gavilán, A.M. Sánchez-Pérez, M. Gurruchaga M. Azkargorta, F. Elortza, M. Martinez-Ibañez, I. Iloro, J. Suay, I. Goñi, Characterization of serum proteins attached to distinct sol-gel hybrid surfaces, J. Biomed. Mater. Res. Part B Appl. Biomater. (2017) 1-9, https://doi.org/ 10.1002/jbm.b.33954.

[18] Z. Zhen, Y. Zheng, Z. Ge, C. Lai, T. Xi, Biological effect and molecular mechanism study of biomaterials based on proteomic research, J. Mat. Sci. Technol. 33 (2017) 607-615, https://doi.org/10.1016/j.jmst.2017.01.001.

[19] S. Franz, S. Rammelt, D. Scharnweber, J.C. Simon, Immune responses to implants - a review of the implications for the design of immunomodulatory biomaterials, Biomaterials 32 (2011) 6692-6709, https://doi.org/10.1016/ j.biomaterials.2011.05.078.

[20] D.D. Deligianni, N.D. Katsala, P.G. Koutsoukos, Y.F. Missirlis, Effect of surface roughness of hydroxyapatite on human bone marrow cell adhesion, proliferation, Differ. Detachment Strength 22 (2001) 87-96.

[21] S. Best, B. Sim, M. Kayser, S. Downes, The dependence of osteoblastic response on variations in the chemical composition and physical properties of hydroxyapatite, J. Mater. Sci. Mater. Med. 8 (1997) 97-103, https:// doi.org/10.1023/A:1018558816871.

[22] D.R. Villarreal, A. Sogal, J.L. Ong, Protein adsorption and osteoblast responses to different calcium phosphate surfaces, J. Oral Implantol. 24 (1998) 67-73, 
https://doi.org/10.1563/1548-1336(1998)024<0067:PAAORT>2.3.CO;2.

[23] K.G. Battiston, J.W.C. Cheung, D. Jain, J.P. Santerre, Biomaterials in co-culture systems: towards optimizing tissue integration and cell signaling within scaffolds, Biomaterials 35 (2014) 4465-4476, https://doi.org/10.1016/ j.biomaterials.2014.02.023.

[24] M.D. Swartzlander, C.A. Barnes, A.K. Blakney, J.L. Kaar, T.R. Kyriakides, S.J. Bryant, Linking the foreign body response and protein adsorption to PEGbased hydrogels using proteomics, Biomaterials 41 (2015) 26-36, https:// doi.org/10.1016/j.biomaterials.2014.11.026.

[25] M.H. Yang, S.S. Yuan, T.W. Chung, S. Bin Jong, C.Y. Lu, W.C. Tsai, W.C. Chen, P.C. Lin, P.W. Chiang, Y.C. Tyan, Characterization of silk fibroin modified surface: a proteomic view of cellular response proteins induced by biomaterials, Biomed. Res. Int. 2014 (2014), https://doi.org/10.1155/2014/ 209469.

[26] P. Roach, D. Farrar, C.C. Perry, Interpretation of protein adsorption: surfaceinduced conformational changes, J. Am. Chem. Soc. 127 (2005) 8168-8173, https://doi.org/10.1021/ja0428980.

[27] C.S. Kim, K.J. Lee, J.E. Kim, Y.G. Park, J.J. Ryu, H.R. Kim, Proteomic analysis of the biological response of MG63 osteoblast-like cells to titanium implants, Odontology 102 (2014) 241-248, https://doi.org/10.1007/s10266-013-01154

[28] T. Akkas, C. Citak, A. Sirkecioglu, F.S. Güner, Which is more effective for protein adsorption: surface roughness, surface wettability or swelling? Case study of polyurethane films prepared from castor oil and poly(ethylene glycol), Polym. Int. 62 (2013) 1202-1209, https://doi.org/10.1002/pi.4408.

[29] X. Yu, X. Tang, S.V. Gohil, C.T. Laurencin, Biomaterials for bone regenerative engineering, Adv. Healthc. Mater. 4 (2015) 1268-1285, https://doi.org/ 10.1002/adhm.201400760.

[30] L.T. Allen, M. Tosetto, I.S. Miller, D.P. O'Connor, S.C. Penney, I. Lynch, A.K. Keenan, S.R. Pennington, K.A. Dawson, W.M. Gallagher, Surface-induced changes in protein adsorption and implications for cellular phenotypic responses to surface interaction, Biomaterials 27 (2006) 3096-3108, https:// doi.org/10.1016/j.biomaterials.2006.01.019.

[31] S.S. Davis, An introduction to tissue-biomaterial interactions, J. Contr. Release 93 (2003) 85, https://doi.org/10.1016/S0168-3659(03)00331-6.

[32] M.R. Wilkins, J.C. Sanchez, A.A. Gooley, R.D. Appel, I. Humphery-Smith, D.F. Hochstrasser, K.L. Williams, Progress with proteome projects: why all proteins expressed by a genome should be identified and how to do it, Biotechnol. Genet. Eng. Rev. 13 (1996) 19-50, https://doi.org/10.1080/ 02648725.1996.10647923.

[33] R.P. Horgan, L.C. Kenny, SAC review " Omic " technologies : proteomics and metabolomics, Obstet. Gynaecol. 13 (2011) 189-195, https://doi.org/ 10.1576/toag.13.3.189.27672.

[34] P.R. Graves, T.A.J. Haystead, Molecular Biologist's guide to proteomics, Microbiol. Mol. Biol. Rev. 66 (2002) 39-63, https://doi.org/10.1128/ MMBR.66.1.39-63.2002.

[35] Z. Zhang, S. Wu, D.L. Stenoien, L. Paša-Tolić, High-throughput proteomics, Annu. Rev. Anal. Chem. 7 (2014) 427-454, https://doi.org/10.1146/annurevanchem-071213-020216.

[36] T. Nilsson, M. Mann, R. Aebersold, J.R. Yates, A. Bairoch, J.J.M. Bergeron, Mass spectrometry in high-throughput proteomics: ready for the big time, Nat. Methods 7 (2010) 681-685, https://doi.org/10.1038/nmeth0910-681.

[37] S.D. Patterson, R.H. Aebersold, Proteomics: the first decade and beyond, Nat. Genet. 33 (2003) 311-323, https://doi.org/10.1038/ng1106.

[38] I.C. Guerrera, O. Kleiner, Application of Mass Spectrometry in Proteomics, vol. 25, 2005, pp. 71-93, https://doi.org/10.1007/s10540-005-2849-X.

[39] K. Chandramouli, P.-Y. Qian, Proteomics: challenges, techniques and possibilities to overcome biological sample complexity, Hum. Genom. Proteomics 2009 (2009) 22, https://doi.org/10.4061/2009/239204.

[40] C.C. Wu, M.J. MacCoss, Shotgun proteomics: tools for the analysis of complex biological systems, Curr. Opin. Mol. Ther. 4 (2002) 242-250. http://www. ncbi.nlm.nih.gov/pubmed/12139310.

[41] D.A. Wolters, M.P. Washburn, J.R. Yates, An automated multidimensional protein identification technology for shotgun proteomics, Anal. Chem. 73 (2001) 5683-5690, https://doi.org/10.1021/ac010617e.

[42] R. Higdon, E. Kolker, Can "normal" protein expression ranges be estimated with high-throughput proteomics? J. Proteome Res. 14 (2015) 2398-2407, https://doi.org/10.1021/acs.jproteome.5b00176.

[43] K.A. Power, K.T. Fitzgerald, W.M. Gallagher, Examination of cell-host-biomaterial interactions via high-throughput technologies: a reappraisal, Biomaterials 31 (2010) 6667-6674, https://doi.org/10.1016/ j.biomaterials.2010.05.029.

[44] L. Tang, M.S. Sheu, T. Chu, Y.H. Huang, Anti-inflammatory properties of triblock siloxane copolymer-blended materials, Biomaterials 20 (1999) 1365-1370, https://doi.org/10.1016/S0142-9612(99)00034-4.

[45] M. Kastantin, B.B. Langdon, D.K. Schwartz, A bottom-up approach to understanding protein layer formation at solid-liquid interfaces, Adv. Colloid Interface Sci. 207 (2014) 240-252, https://doi.org/10.1016/j.cis.2013.12.006.

[46] M. Rabe, D. Verdes, S. Seeger, Understanding protein adsorption phenomena at solid surfaces, Adv. Colloid Interface Sci. 162 (2011) 87-106, https:// doi.org/10.1016/j.cis.2010.12.007.

[47] L. Tang, J.W. Eaton, Inflammatory responses to biomaterials, Am. J. Clin. Pathol. 103 (1995) 466-471, https://doi.org/10.1093/ajcp/103.4.466.

[48] V. Balasubramanian, N.K. Grusin, R.W. Bucher, V.T. Turitto, S.M. Slack, Residence-time dependent changes in fibrinogen adsorbed to polymeric biomaterials, J. Biomed. Mater. Res. 44 (1999) 253-260, https://doi.org/ 10.1002/(SICI)1097-4636(19990305)44, 3<253:AID-JBM3>3.0.CO;2-K.

[49] A.E. Engberg, P.H. Nilsson, S. Huang, K. Fromell, O.A. Hamad, T.E. Mollnes, J.P. Rosengren-Holmberg, K. Sandholm, Y. Teramura, I.A. Nicholls, B. Nilsson, K.N. Ekdahl, Prediction of inflammatory responses induced by biomaterials in contact with human blood using protein fingerprint from plasma, Biomaterials $36 \quad$ (2015) 55-65, https://doi.org/10.1016/ j.biomaterials.2014.09.011.

[50] K. Kottke-Marchant, J.M. Anderson, Y. Umemura, R.E. Marchant, Effect of albumin coating on the in vitro blood compatibility of Dacron ${ }^{\circledR}$ arterial prostheses, Biomaterials 10 (1989) 147-155, https://doi.org/10.1016/01429612(89)90017-3.

[51] J.R. Keogh, J.W. Eaton, Albumin binding surfaces for biomaterials, J. Lab. Clin. Med. 124 (1994) 537-545.

[52] L. Tang, a H. Lucas, J.W. Eaton, Inflammatory responses to implanted polymeric biomaterials: role of surface-adsorbed immunoglobulin G, J. Lab. Clin. Med. 122 (1993) 292-300, 0022-2143(93)90076-B ([pii]).

[53] L. Tang, J.W. Eaton, Fibrin(ogen) mediates acute inflammatory responses to biomaterials, J. Exp. Med. 178 (1993) 2147-2156, https://doi.org/10.1084/ jem.178.6.2147.

[54] L.M. Szott, T.A. Horbett, Protein interactions with surfaces: cellular responses, complement activation, and newer methods, Curr. Opin. Chem. Biol. 15 (2011) 677-682, https://doi.org/10.1016/j.cbpa.2011.04.021.

[55] L.C. Xu, J.W. Bauer, C.A. Siedlecki, Proteins, platelets, and blood coagulation at biomaterial interfaces, Colloids Surf. B Biointerfaces 124 (2014) 49-68, https://doi.org/10.1016/j.colsurfb.2014.09.040.

[56] W.B. Tsai, J.M. Grunkemeier, T.A. Horbett, Human plasma fibrinogen adsorption and platelet adhesion to polystyrene, J. Biomed. Mater. Res. 44 (1999) 130-139, https://doi.org/10.1002/(SICI)1097-4636(199902)44, 2<130::AID-JBM2>3.0.CO;2-9.

[57] T. Mohan, K. Niegelhell, C. Nagaraj, D. Reishofer, S. Spirk, A. Olschewski, K. Stana Kleinschek, R. Kargl, Interaction of tissue engineering substrates with serum proteins and its influence on human primary endothelial cells, Biomacromolecules 18 (2017) 413-421, https://doi.org/10.1021/ acs.biomac.6b01504.

[58] N.M. Coelho, C. Gonzalez-Garcia, M. Salmeron-Sanchez, G. Altankov, Arrangement of type IV collagen on $\mathrm{NH} 2$ and $\mathrm{COOH}$ functionalized surfaces, Biotechnol. Bioeng. 108 (2011) 3009-3018, https://doi.org/10.1002/ bit.23265.

[59] A. Diener, B. Nebe, F. Lüthen, P. Becker, U. Beck, H.G. Neumann, J. Rychly, Control of focal adhesion dynamics by material surface characteristics, Bio-

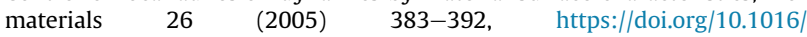
j.biomaterials.2004.02.038.

[60] M.S. Wang, L.B. Palmer, J.D. Schwartz, A. Razatos, Evaluating Protein Attraction and Adhesion to Biomaterials with the Atomic Force Microscope, 2004, pp. 7753-7759.

[61] M. Holmberg, X. Hou, Fibrinogen adsorption on blocked surface of albumin Colloids Surf. B Biointerfaces 84 (2011) 71-75, https://doi.org/10.1016/ j.colsurfb.2010.12.016.

[62] X. Wang, D.R. Schmidt, E.J. Joyce, W.J. Kao, Application of MS-based proteomics to study serum protein adsorption/absorption and complement C3 activation on poly(ethylene glycol) hydrogels, J. Biomater. Sci. Polym. Ed. 22 (2011) 1343-1362, https://doi.org/10.1163/092050610X508400.

[63] V. Serpooshan, M. Mahmoudi, M. Zhao, Protein corona influences cell-biomaterial interactions in nanostructured tissue engineering scaffolds, Adv. Funct. 25 (2015) 4379-4389, https://doi.org/10.1002/ adfm.201500875.Protein.

[64] R.D. Oleschuk, M.E. Mccomb, A. Chow, W. Ens, K.G. Standing, H. Perreault Y. Marois, M. King, Characterization of plasma proteins adsorbed onto biomaterials by MALDI-TOFMS, Biomaterials 21 (2000) 1701-1710, https:// doi.org/10.1016/S0142-9612(00)00054-5.

[65] C.G. Dodo, P.M. Senna, W. Custodio, A.F. Paes Leme, A.A. Del Bel Cury, Proteome analysis of the plasma protein layer adsorbed to a rough titanium surface, Biofouling 29 (2013) 549-557, https://doi.org/10.1080 08927014.2013 .787416$.

[66] M. Hammad, W. Rao, J.G.W. Smith, D.G. Anderson, R. Langer, L.E. Young, D.A. Barrett, M.C. Davies, C. Denning, M.R. Alexander, Identification of polymer surface adsorbed proteins implicated in pluripotent human embryonic stem cell expansion, Biomater. Sci. 4 (2016) 1381-1391, https:// doi.org/10.1039/C6BM00214E.

[67] M.-N. Abdallah, S.D. Tran, G. Abughanam, M. Laurenti, D. Zuanazzi, M.A. Mezour, Y. Xiao, M. Cerruti, W.L. Siqueira, F. Tamimi, Biomaterial surface proteomic signature determines interaction with epithelial cells, Acta Biomater. 54 (2017) 150-163, https://doi.org/10.1016/j.actbio.2017.02.044.

[68] F. Romero-Gavilán, N.C. Gomes, J. Ródenas, A. Sánchez, M. Azkargorta, I. Iloro F. Elortza, I. García Arnáez, M. Gurruchaga, I. Goñi, J. Suay, Proteome analysis of human serum proteins adsorbed onto different titanium surfaces used in dental implants, Biofouling 33 (2017) 98-111, https://doi.org/10.1080/ 08927014.2016.1259414.

[69] K. Sugimoto, S. Tsuchiya, M. Omori, R. Matsuda, M. Fujio, K. Kuroda M. Okido, H. Hibi, Proteomic analysis of bone proteins adsorbed onto the surface of titanium dioxide, Biochem. Biophys. Rep. 7 (2016) 316-322, https://doi.org/10.1016/j.bbrep.2016.07.007.

[70] S. Oughlis, S. Lessim, S. Changotade, F. Bollotte, F. Poirier, G. Helary, J.J. Lataillade, V. Migonney, D. Lutomski, Development of proteomic tools to 
study protein adsorption on a biomaterial, titanium grafted with poly(sodium styrene sulfonate), J. Chromatogr. B 879 (2011) 3681-3687, https:/ doi.org/10.1016/j.jchromb.2011.10.006.

[71] A.F. Khan, M. Saleem, A. Afzal, A. Ali, A. Khan, A.R. Khan, Bioactive behavior of silicon substituted calcium phosphate based bioceramics for bone regeneration, Mater. Sci. Eng. C 35 (2014) 245-252, https://doi.org/10.1016/ j.msec.2013.11.013.

[72] D. Yang, X. Lü, Y. Hong, T. Xi, D. Zhang, The molecular mechanism for effects of TiN coating on NiTi alloy on endothelial cell function, Biomaterials 35 (2014) 6195-6205, https://doi.org/10.1016/j.biomaterials.2014.04.069.

[73] D. Yang, X. Lü, Y. Hong, T. Xi, D. Zhang, The molecular mechanism of mediation of adsorbed serum proteins to endothelial cells adhesion and growth on biomaterials, Biomaterials 34 (2013) 5747-5758, https://doi.org 10.1016/j.biomaterials.2013.04.028.

[74] O. Suzuki, Octacalcium phosphate (OCP)-based bone substitute materials, Jpn. Dent. Sci. Rev. 49 (2013) 58-71, https://doi.org/10.1016/ j.jdsr.2013.01.001.

[75] H. Kaneko, J. Kamiie, H. Kawakami, T. Anada, Y. Honda, N. Shiraishi, S. Kamakura, T. Terasaki, H. Shimauchi, O. Suzuki, Proteome analysis of rat serum proteins adsorbed onto synthetic octacalcium phosphate crystals, Anal. Biochem. 418 (2011) 276-285, https://doi.org/10.1016/ j.ab.2011.07.022

[76] J.R. Delanghe, R. Speeckaert, M.M. Speeckaert, Complement C3 and its polymorphism: biological and clinical consequences, Pathology 46 (2014) 1-10, https://doi.org/10.1097/PAT.0000000000000042.

[77] D.C. Mangham, D.J. Scoones, M.T. Drayson, Complement and the recruitment of mononuclear osteoclasts, J. Clin. Pathol. 46 (1993) 517-521, https:// doi.org/10.1136/jcp.46.6.517.

[78] J. Kamiie, S. Ohtsuki, R. Iwase, K. Ohmine, Y. Katsukura, K. Yanai, Y. Sekine, Y. Uchida, S. Ito, T. Terasaki, Quantitative atlas of membrane transporte proteins: development and application of a highly sensitive simultaneous LC/ MS/MS method combined with novel in-silico peptide selection criteria, Pharm. Res. 25 (2008) 1469-1483, https://doi.org/10.1007/s11095-0089532-4.

[79] M. Bonomini, V. Sirolli, L. Pieroni, P. Felaco, L. Amoroso, A. Urbani, Proteomic investigations into hemodialysis therapy, Int. J. Mol. Sci. 16 (2015) 29508-29521, https://doi.org/10.3390/ijms161226189.

[80] A. Urbani, V. Sirolli, S. Lupisella, S. Levi-Mortera, B. Pavone, L. Pieroni, L. Amoroso, R. Di Vito, S. Bucci, S. Bernardini, P. Sacchetta, M. Bonomini, Proteomic investigations on the effect of different membrane materials on blood protein adsorption during haemodialysis, Blood Transfus. 10 (Suppl 2) (2012) 101-112, https://doi.org/10.2450/2012.014S.

[81] L. Pieroni, S. Levi Mortera, V. Greco, V. Sirolli, M. Ronci, P. Felaco, G. Fucci, S. De Fulviis, R. Massoud, S. Condò, A. Capria, N. Di Daniele, S. Bernardini, A. Urbani, M. Bonomini, Biocompatibility assessment of haemodialysis membrane materials by proteomic investigations, Mol. Biosyst. 11 (2015) 1633-1643, https://doi.org/10.1039/C5MB00058K.

[82] Y. Mei, S. Gerecht, M. Taylor, A.J. Urquhart, S.R. Bogatyrev, S.-W. Cho, M.C. Davies, M.R. Alexander, R.S. Langer, D.G. Anderson, Mapping the interactions among biomaterials, adsorbed proteins, and human embryonic stem cells, Adv. Mater. 21 (2009) 2781-2786, https://doi.org/10.1002/ adma.200803184.

[83] F. Kantawong, K.E.V. Burgess, K. Jayawardena, A. Hart, R.J. Burchmore, N. Gadegaard, R.O.C. Oreffo, M.J. Dalby, Whole proteome analysis of osteoprogenitor differentiation induced by disordered nanotopography and mediated by ERK signalling, Biomaterials 30 (2009) 4723-4731, https:/ doi.org/10.1016/j.biomaterials.2009.05.040

[84] C. Henrionnet, P. Gillet, D. Mainard, J.B. Vincourt, A. Pinzano, Label-free relative quantification of secreted proteins as a non-invasive method for the quality control of chondrogenesis in bioengineered substitutes for cartilage repair, J. Tissue Eng. Regen. Med. 12 (3) (2018) e1757-e1766, https:/ doi.org/10.1002/term.2454.

[85] Z. Zhang, J. Wang, X. Lü, An integrated study of natural hydroxyapatiteinduced osteogenic differentiation of mesenchymal stem cells using transcriptomics, proteomics and microRNA analyses, Biomed. Mater. 9 (2014) https://doi.org/10.1088/1748-6041/9/4/045005.

[86] X. Zhang, Lü Zhiwei, A comparative study of the impact of natural and synthetic hydroxyapatite on mesenchymal stem cell function based on proteomics, Sci. Adv. Mater. 7 (2015) 1611-1623.

[87] M.H. Yang, S.S. Yuan, Y.F. Huang, P.C. Lin, C.Y. Lu, T.W. Chung, Y.C. Tyan, A proteomic view to characterize the effect of chitosan nanoparticle to hepatic cells: is chitosan nanoparticle an enhancer of PI3K/AKT1/mTOR pathway? Biomed. Res. Int. 2014 (2014) https://doi.org/10.1155/2014/ 789591.

[88] A. Banerjee, J. Qi, R. Gogoi, J. Wong, S. Mitragotri, Role of nanoparticle size, shape and surface chemistry in oral drug delivery, J. Contr. Release 238 (2016) 176-185, https://doi.org/10.1016/j.jconrel.2016.07.051.

[89] S. Kumar, A.C. Anselmo, A. Banerjee, M. Zakrewsky, S. Mitragotri, Shape and size-dependent immune response to antigen-carrying nanoparticles, J. Contr. Release 220 (2015) 141-148, https://doi.org/10.1016/j.jconrel.2015.09.069.

[90] J.L. Xu, K.A. Khor, J.J. Sui, J.H. Zhang, W.N. Chen, Protein expression profiles in osteoblasts in response to differentially shaped hydroxyapatite nanoparticles, Biomaterials 30 (2009) 5385-5391, https://doi.org/10.1016 j.biomaterials.2009.07.002.

[91] N. Bertrand, P. Grenier, M. Mahmoudi, E.M. Lima, E.A. Appel, F. Dormont
J.M. Lim, R. Karnik, R. Langer, O.C. Farokhzad, Mechanistic understanding of in vivo protein corona formation on polymeric nanoparticles and impact on pharmacokinetics, Nat. Commun. 8 (2017), https://doi.org/10.1038/s41467017-00600-w.

[92] D. Docter, S. Strieth, D. Westmeier, O. Hayden, M. Gao, S.K. Knauer, R.H. Stauber, No king without a crown - impact of the nanomaterial-protein corona on nanobiomedicine, Nanomedicine 10 (2015) 503-519, https:// doi.org/10.2217/nnm.14.184.

[93] L. Landgraf, C. Christner, W. Storck, I. Schick, I. Krumbein, H. Dähring, K. Haedicke, K. Heinz-Herrmann, U. Teichgräber, J.R. Reichenbach, W. Tremel, S. Tenzer, I. Hilger, A plasma protein corona enhances the biocompatibility of Au@Fe3O4 Janus particles, Biomaterials 68 (2015) 77-88, https://doi.org/10.1016/j.biomaterials.2015.07.049.

[94] C.D. Walkey, J.B. Olsen, H. Guo, A. Emili, W.C.W. Chan, Nanoparticle size and surface chemistry determine serum protein adsorption and macrophage uptake, J. Am. Chem. Soc. 134 (2012) 2139-2147, https://doi.org/10.1021/ ja2084338.

[95] E. Fröhlich, Role of omics techniques in the toxicity testing of nanoparticles, J. Nanobiotechnol. 15 (2017), https://doi.org/10.1186/s12951-017-0320-3.

[96] S. Lorscheidt, A. Lamprecht, Safety assessment of nanoparticles for drug delivery by means of classic in vitro assays and beyond, Expert Opin. Drug Deliv. $13 \quad$ (2016) 1545-1558, https://doi.org/10.1080/ 17425247.2016.1198773.

[97] M. Matysiak, L. Kapka-Skrzypczak, K. Brzóska, A.C. Gutleb, M. Kruszewski, Proteomic approach to nanotoxicity, J. Proteomics 137 (2016) 35-44, https://doi.org/10.1016/j.jprot.2015.10.025.

[98] Z.W. Lai, Y. Yan, F. Caruso, E.C. Nice, Emerging techniques in proteomics for probing nano-bio interactions, ACS Nano 6 (2012) 10438-10448, https:// doi.org/10.1021/nn3052499.

[99] F. Heravi, M. Ramezani, M. Poosti, M. Hosseini, A. Shajiei, F. Ahrari, Vitro cytotoxicity assessment of an orthodontic composite containing titaniumdioxide nano-particles, J. Dent. Res. Dent. Clin. Dent. Prospects 7 (2013) 192-198, https://doi.org/10.5681/joddd.2013.031.

[100] Y. Gao, N.V. Gopee, P.C. Howard, Proteomic analysis of early response lymph node proteins in mice treated with titanium dioxide nanoparticles, J. Proteomics 74 (2011) 2745-2759, https://doi.org/10.1016/ j.jprot.2011.08.009.

[101] L. Armand, M. Biola-Clier, L. Bobyk, V. Collin-Faure, H. Diemer, J.M. Strub, S. Cianferani, A. Van Dorsselaer, N. Herlin-Boime, T. Rabilloud, M. Carriere, Molecular responses of alveolar epithelial A549 cells to chronic exposure to titanium dioxide nanoparticles: a proteomic view, J. Proteomics 134 (2016) 163-173, https://doi.org/10.1016/j.jprot.2015.08.006.

[102] M. Zhao, H. Li, X. Liu, J. Wei, J. Ji, S. Yang, Z. Hu, S. Wei, Response of human osteoblast to n-HA/PEEK-quantitative proteomic study of bio-effects of nano-hydroxyapatite composite, Sci. Rep. 6 (2016), https://doi.org/10.1038/ srep22832, 22832, http://www.nature.com/articles/ srep22832\#supplementary-information.

[103] J. Xu, A.K. Khiam, J. Sui, J. Zhang, L.T. Tuan, N.C. Wei, Comparative proteomics profile of osteoblasts cultured on dissimilar hydroxyapatite biomaterials: an iTRAQ-coupled 2-D LC-MS/MS analysis, Proteomics 8 (2008) 4249-4258, https://doi.org/10.1002/pmic.200800103.

[104] S. Van Rijt, P. Habibovic, Enhancing regenerative approaches with nanoparticles, J. R. Soc. Interface 14 (2017) 1-10, https://doi.org/10.1098/ rsif.2017.0093.

[105] J. Godwin, D. Kuraitis, N. Rosenthal, Extracellular matrix considerations for scar-free repair and regeneration: insights from regenerative diversity among vertebrates, Int. J. Biochem. Cell Biol. 56 (2014) 47-55, https:// doi.org/10.1016/j.biocel.2014.10.011.

[106] K.E.M. Benders, P.R. van Weeren, S.F. Badylak, D.B.F. Saris, W.J.A. Dhert, J. Malda, Extracellular matrix scaffolds for cartilage and bone regeneration, Trends Biotechnol. 31 (2013) 169-176, https://doi.org/10.1016/ j.tibtech.2012.12.004.

[107] J.A. Hubbell, Materials as morphogenetic guides in tissue engineering, Curr. Opin. Biotechnol. 14 (2003) 551-558, https://doi.org/10.1016/ j.copbio.2003.09.004

[108] Q. Li, B.E. Uygun, S. Geerts, S. Ozer, M. Scalf, S.E. Gilpin, H.C. Ott M.L. Yarmush, L.M. Smith, N.V. Welham, B.L. Frey, Proteomic analysis of naturally-sourced biological scaffolds, Biomaterials 75 (2016) 37-46, https:// doi.org/10.1016/j.biomaterials.2015.10.011.

[109] C.S. Hughes, L.M. Postovit, G.A. Lajoie, Matrigel: a complex protein mixture required for optimal growth of cell culture, Proteomics 10 (2010) 1886-1890, https://doi.org/10.1002/pmic.200900758.

[110] R.C. de Guzman, M.R. Merrill, J.R. Richter, R.I. Hamzi, O.K. Greengauz-Roberts, M.E. Van Dyke, Mechanical and biological properties of keratose biomaterials, Biomaterials 32 (2011) 8205-8217, https://doi.org/10.1016/ j.biomaterials.2011.07.054.

[111] M.E. Furth, A. Atala, M.E. Van Dyke, Smart biomaterials design for tissue engineering and regenerative medicine, Biomaterials 28 (2007) 5068-5073, https://doi.org/10.1016/j.biomaterials.2007.07.042.

[112] W.F. Wolkers, A.H. Ker, Freeze-drying of decellularized heart valve tissues, Methods Mol. Biol. 1257 (2015) 499-506, https://doi.org/10.1007/978-14939-2193-5_26.

[113] J.D. O'Neill, R. Anfang, A. Anandappa, J. Costa, J. Javidfar, H.M. Wobma, G. Singh, D.O. Freytes, M.D. Bacchetta, J.R. Sonett, G. Vunjak-Novakovic, Decellularization of human and porcine lung tissues for pulmonary tissue 
engineering, in: Ann. Thorac. Surg, 2013, pp. 1046-1055, https://doi.org/ 10.1016/j.athoracsur.2013.04.022.

[114] R. Wilson, E.L. Norris, B. Brachvogel, C. Angelucci, S. Zivkovic, L. Gordon, B.C. Bernardo, J. Stermann, K. Sekiguchi, J.J. Gorman, J.F. Bateman, Changes in the chondrocyte and extracellular matrix proteome during post-natal mouse cartilage development, Mol. Cell. Proteomics 11 (2012), https://doi.org/ 10.1074/mcp.M111.014159. M111.014159.

[115] D. Guo, W. Tan, F. Wang, Z. Lv, J. Hu, T. Lv, Q. Chen, X. Gu, B. Wan, Z. Zhang, Proteomic analysis of human articular cartilage: identification of differentially expressed proteins in knee osteoarthritis, Jt. Bone. Spine 75 (2008) 439-444, https://doi.org/10.1016/j.jbspin.2007.12.003.

[116] M.F. Hsueh, A. Khabut, S. Kjellström, P. Önnerfjord, V.B. Kraus, Elucidating the molecular composition of cartilage by proteomics, J. Proteome Res. 15 (2016) 374-388, https://doi.org/10.1021/acs.jproteome.5b00946.

[117] E.A. Calle, R.C. Hill, K.L. Leiby, A.V. Le, A.L. Gard, J.A. Madri, K.C. Hansen, L.E. Niklason, Targeted proteomics effectively quantifies differences between native lung and detergent-decellularized lung extracellular matrices, Acta Biomater. 46 (2016) 91-100, https://doi.org/10.1016/j.actbio.2016.09.043.

[118] R.C. Hill, E.A. Calle, M. Dzieciatkowska, L.E. Niklason, K.C. Hansen, Quantification of extracellular matrix proteins from a rat lung scaffold to provide a molecular readout for tissue engineering, Mol. Cell. Proteomics 14 (2015) 961-973, https://doi.org/10.1074/mcp.M114.045260.

[119] M.E.L. Nienhuijs, K. Poulsen, M. Van Der Zande, A. Briest, M.A.W. Merkx, P.J.W. Stoelinga, O.N. Jensen, J.A. Jansen, X.F. Walboomers, Analytical assessment of the osteoinductive material COLLOSSE, J. Biomed. Mat. Res. Part B Appl. Biomater. 89 (2009) 300-305, https://doi.org/10.1002/ jbm.b.31216.

[120] C.S. Hughes, L. Radan, D. Betts, L.M. Postovit, G.A. Lajoie, Proteomic analysis of extracellular matrices used in stem cell culture, Proteomics 11 (2011) 3983-3991, https://doi.org/10.1002/pmic.201100030.

[121] D. Soteriou, B. Iskender, A. Byron, J.D. Humphries, S. Borg-Bartolo, M.C. Haddock, M.A. Baxter, D. Knight, M.J. Humphries, S.J. Kimber, Comparative proteomic analysis of supportive and unsupportive extracellular matrix substrates for human embryonic stem cell maintenance, J. Biol. Chem. 288 (2013) 18716-18731, https://doi.org/10.1074/jbc.M113.463372.

[122] Y. Yan, L.M. Martin, D.B. Bosco, J.L. Bundy, R.S. Nowakowski, Q.X.A. Sang, Y. Li, Differential effects of acellular embryonic matrices on pluripotent stem cell expansion and neural differentiation, Biomaterials 73 (2015) 231-242, https://doi.org/10.1016/j.biomaterials.2015.09.020.

[123] A. Baranowski, A. Klein, U. Ritz, A. Ackermann, J. Anthonissen, K.B. Kaufmann, C. Brendel, H. Götz, P.M. Rommens, A. Hofmann, Surface functionalization of orthopedic titanium implants with bone sialoprotein, PLoS One 11 (2016), https://doi.org/10.1371/journal.pone.0153978.

[124] M.E.L. Nienhuijs, K. Poulsen, M. Van Der Zande, A. Briest, M.A.W. Merkx, P.J.W. Stoelinga, O.N. Jensen, J.A. Jansen, X.F. Walboomers, Analytical assessment of the osteoinductive material COLLOSS??E, J. Biomed. Mat. Res. Part B Appl. Biomater. 89 (2009) 300-305, https://doi.org/10.1002/ jbm.b.31216.

[125] R.C. de Guzman, M.R. Merrill, J.R. Richter, R.I. Hamzi, O.K. Greengauz-Roberts, M.E. Van Dyke, Mechanical and biological properties of keratose biomaterials, Biomaterials 32 (2011) 8205-8217, https://doi.org/10.1016/ j.biomaterials.2011.07.054.

[126] J.G. Meyer, B. Schilling, Clinical applications of quantitative proteomics using targeted and untargeted data-independent acquisition techniques, Expert Rev. Proteomics 14 (2017) 419-429, https://doi.org/10.1080/ 14789450.2017.1322904.

[127] V.P. Galván-Chacón, P. Habibovic, Deconvoluting the bioactivity of calcium phosphate-based bone graft substitutes: strategies to understand the role of individual material properties, Adv. Healthc. Mater 1601478 (2017) 1601478, https://doi.org/10.1002/adhm.201601478.

[128] N. Groen, M. Guvendiren, H. Rabitz, W.J. Welsh, J. Kohn, J. De Boer, Stepping into the omics era: opportunities and challenges for biomaterials science and engineering, Acta Biomater. 34 (2016) 133-142, https://doi.org/10.1016/ j.actbio.2016.02.015.

[129] R.D. Addie, B. Balluff, J.V.M.G. Bovée, H. Morreau, L.A. McDonnell, Current state and future challenges of mass spectrometry imaging for clinical research, Anal. Chem. 87 (2015) 6426-6433, https://doi.org/10.1021/ acs.analchem.5b00416.

[130] S.A. Schwartz, R.M. Caprioli, Imaging Mass Spectrometry: Viewing the Future, Humana Press, Totowa, NJ, Totowa, 2010. https://doi.org/10.1007/ 978-1-60761-746-4_1.

[131] L.J. Gamble, C.R. Anderton, Secondary ion mass spectrometry imaging tissue, cells and microbial systems, Micros. Today 24 (2017) 24-31, https://doi.org/ 10.1017/S1551929516000018.Secondary.

[132] M. Aichler, A. Walch, MALDI Imaging mass spectrometry: current frontiers and perspectives in pathology research and practice, Lab. Investig. 95 (2015) 422-431, https://doi.org/10.1038/labinvest.2014.156.

[133] N. Georgi, B. Cillero-Pastor, G.B. Eijkel, P.C. Periyasamy, A. Kiss, C. Van Blitterswijk, J.N. Post, R.M.A. Heeren, M. Karperien, Differentiation of mesenchymal stem cells under hypoxia and normoxia: lipid profiles revealed by time-of-flight secondary ion mass spectrometry and multivariate analysis, Anal. Chem. 87 (2015) 3981-3988, https://doi.org/10.1021/ acs.analchem.5b00114.

[134] A. Henss, M. Rohnke, T. El Khassawna, P. Govindarajan, G. Schlewitz, C. Heiss, J. Janek, Applicability of ToF-SIMS for monitoring compositional changes in bone in a long-term animal model, J. R. Soc. Interface 10 (2013) 20130332, https://doi.org/10.1098/rsif.2013.0332.

[135] C. Eriksson, P. Malmberg, H. Nygren, Time-of-flight secondary ion mass spectrometric analysis of the interface between bone and titanium implants, Rapid Commun. Mass Spectrom. 22 (2008) 943-949, https://doi.org/ $10.1002 / \mathrm{rcm} .3445$.

[136] B.J. Tyler, G. Rayal, D.G. Castner, Multivariate analysis strategies for processing ToF-SIMS images of biomaterials, Biomaterials 28 (2007) 2412-2423, https://doi.org/10.1016/j.biomaterials.2007.02.002.

[137] M.S. Wagner, D.G. Castner, Characterization of adsorbed protein films by time-of-flight secondary ion mass spectrometry with principal component analysis, Langmuir 17 (2001) 4649-4660, https://doi.org/10.1021/ la001209t.

[138] C. Brüning, S. Hellweg, S. Dambach, D. Lipinsky, H.F. Arlinghaus, Improving the interpretation of ToF-SIMS measurements on adsorbed proteins using PCA, in: Surf. Interface Anal, 2006, pp. 191-193, https://doi.org/10.1002/ sia.2233.

[139] Y. Ilin, M.L. Kraft, Secondary ion mass spectrometry and Raman spectroscopy for tissue engineering applications, Curr. Opin. Biotechnol. 31 (2015) 108-116, https://doi.org/10.1016/j.copbio.2014.10.011.

[140] N. Ogrinc Potočnik, G.L. Fisher, A. Prop, R.M.A. Heeren, Sequencing and identification of endogenous neuropeptides with matrix-enhanced secondary ion mass spectrometry tandem mass spectrometry, Anal. Chem. 89 (2017) 8223-8227, https://doi.org/10.1021/acs.analchem.7b02573.

[141] V. Mainini, G. Bovo, C. Chinello, E. Gianazza, M. Grasso, G. Cattoretti, F. Magni Detection of high molecular weight proteins by MALDI imaging mass spectrometry, Mol. Biosyst. 9 (2013) 1101, https://doi.org/10.1039/c2mb25296a.

[142] M. Kompauer, S. Heiles, B. Spengler, Atmospheric pressure MALDI mass spectrometry imaging of tissues and cells at $1.4-\mu \mathrm{m}$ lateral resolution, Nat. Methods 14 (2016) 90-96, https://doi.org/10.1038/nmeth.4071.

[143] R.L. Hansen, Y.J. Lee, High-spatial resolution mass spectrometry imaging: toward single cell metabolomics in plant tissues, Chem. Rec. 18 (1) (2018) 65-77, https://doi.org/10.1002/tcr.201700027.

[144] A. Zavalin, J. Yang, K. Hayden, M. Vestal, R.M. Caprioli, Tissue protein imaging at $1 \mu \mathrm{m}$ laser spot diameter for high spatial resolution and high imaging speed using transmission geometry MALDI TOF MS, Anal. Bioanal. Chem. 407 (2015) 2337-2342, https://doi.org/10.1007/s00216-015-8532-6.

[145] S.M. Fröhlich, M. Eilenberg, A. Svirkova, C. Grasl, R. Liska, H. Bergmeister M. Marchetti-Deschmann, Mass spectrometric imaging of in vivo protein and lipid adsorption on biodegradable vascular replacement systems, Analyst 140 (2015) 6089-6099, https://doi.org/10.1039/C5AN00921A.

[146] B. Cillero-Pastor, R.M.A. Heeren, Matrix-assisted laser desorption ionization mass spectrometry imaging for peptide and protein analyses: a critical review of on-tissue digestion, J. Proteome Res. 13 (2014) 325-335, https:// doi.org/10.1021/pr400743a.

[147] D. Taverna, F. Boraldi, G. De Santis, R.M. Caprioli, D. Quaglino, Histologydirected and imaging mass spectrometry: an emerging technology in ectopic calcification, Bone 74 (2015) 83-94, https://doi.org/10.1016/ j.bone.2015.01.004.

[148] C. Ouyang, B. Chen, L. Li, High throughput in situ DDA analysis of neuropeptides by coupling novel multiplex mass spectrometric imaging (MSI) with gas-phase fractionation, J. Am. Soc. Mass Spectrom. 26 (2015) 1992-2001, https://doi.org/10.1007/s13361-015-1265-0.

[149] K.A. Douglass, A.R. Venter, Protein analysis by desorption electrospray ionization mass spectrometry and related methods, J. Mass Spectrom. 48 (2013) 553-560, https://doi.org/10.1002/jms.3206.

[150] W. Rao, A.D. Celiz, D.J. Scurr, M.R. Alexander, D.A. Barrett, Ambient DESI and LESA-MS analysis of proteins adsorbed to a biomaterial surface using in-situ surface tryptic digestion, J. Am. Soc. Mass Spectrom. 24 (2013) 1927-1936, https://doi.org/10.1007/s13361-013-0737-3.

[151] M. Dilillo, D. Pellegrini, R. Ait-Belkacem, E.L. De Graaf, M. Caleo, L.A. McDonnell, Mass spectrometry imaging, laser capture microdissection, and LC-MS/MS of the same tissue section, J. Proteome Res. 16 (2017) 2993-3001, https://doi.org/10.1021/acs.jproteome.7b00284. 